Mayrhuber, E.S., Dückers, M.L.A., Wallner, P., Arnberger, A., Allex, B., Wiesbock, L., Wanka, Af Kolland, F., Eder, R., Hutter, H.P., Kutalek, R. Vulnerability to heatwaves and implications for public health interventions - A scoping review. Environmental Research: 2018, 166(10), $42-54$

\begin{tabular}{|l|l|}
\hline $\begin{array}{l}\text { Postprint } \\
\text { Version }\end{array}$ & 1.0 \\
\hline Journal website & https://www.sciencedirect.com/science/article/pii/S0013935118302706 \\
\hline Pubmed link & $\underline{\text { https://www.ncbi.nlm.nih.gov/pubmed/29859940 }}$ \\
\hline DOI & $10.1016 /$ j.envres.2018.05.021
\end{tabular}

This is a NIVEL certified Post Print, more info at http://www.nivel.eu

\title{
Vulnerability to heatwaves and implications for public health interventions - A scoping review
}

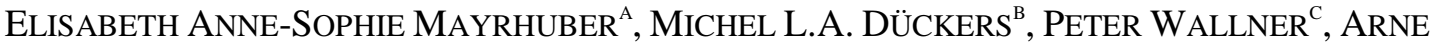 \\ ARNBERGER $^{\mathrm{D}}$, BRIGITTE ALLEX $^{\mathrm{D}}$, LAURA WIESBÖCK $^{\mathrm{E}}$, ANNA WANKA $^{\mathrm{E}}$, FRANZ KOLLAND $^{\mathrm{E}}$, \\ RENATE EDER ${ }^{\mathrm{D}}$, HANS-PETER HUTTER ${ }^{\mathrm{C}}$, RUTH KUTALEK ${ }^{\mathrm{A}}$, \\ ${ }^{a}$ Unit Medical Anthropology and Global Health, Department of Social and Preventive \\ Medicine, Center for Public Health, Medical University of Vienna, Austria \\ ${ }^{b}$ Netherlands Institute for Health Services Research (NIVEL), Utrecht, The Netherlands \\ ${ }^{c}$ Department of Environmental Health, Center for Public Health, Medical University of \\ Vienna, Austria \\ ${ }^{d}$ Institute of Landscape Development, Recreation and Conservation Planning, University of \\ Natural Resources and Life Sciences, Vienna, Austria \\ ${ }^{e}$ Department of Sociology, University of Vienna, Vienna, Austria
}

\begin{abstract}
Background: Heatwaves form a serious public health threat, especially for vulnerable groups. Interventions such as active outreach programs, exposure reduction measures and monitoring and mapping of at-risk groups are increasingly implemented across the world but little is known about their effect. Objectives: To assess how vulnerable groups are identified and reached in heat health interventions, to understand the effectiveness and efficiency of those interventions, and to identify research gaps in existing literature.

Methods: We performed a literature search in relevant scientific literature databases and searched with a four element search model for articles published from 1995 onward. We extracted data on intervention measures, target group and evaluation of effectiveness and efficiency.

Results: We identified 23 eligible studies. Patterns exist in type of interventions 1) to detect and 2) to influence extrinsic and intrinsic risk and protective factors. Results showed several intervention barriers related to the variety and intersection of these factors, as well as the self-perception of vulnerable groups, and misconceptions and unfavorable attitudes towards intervention benefits. While modest indications for the evidence on the effectiveness of interventions were found, efficiency remains unclear.

Discussion: Interventions entailed logical combinations of measures, subsumed as packages. Evidence for effective and efficient intervention is limited by the difficulty to determine effects and because single measures are mutually dependent. Interventions prioritized promoting behavioral change and were
\end{abstract}


Mayrhuber, E.S., Dückers, M.L.A., Wallner, P., Arnberger, A., Allex, B., Wiesbock, L., Wanka, A Kolland, F., Eder, R., Hutter, H.P., Kutalek, R. Vulnerability to heatwaves and implications for public health interventions - A scoping review. Environmental Research: 2018, 166(10), $42-54$

based on behavioral assumptions that remain untested and mechanisms not worked out explicitly.

Conclusions: Multifaceted efforts are needed to tailor interventions, compiled in heat health warning systems and action plans for exposure reduction and protection of vulnerable populations, to fit the social, economic and geographical context. Besides adequately addressing relevant risk and protective factors, the challenge is to integrate perspectives of vulnerable groups. Future research should focus on intervention barriers and improving the methods of effectiveness and efficiency evaluation.

\section{INTRODUCTION}

Climate change induced natural hazards such as extreme heat events have adverse health effects especially in vulnerable groups (Dukes-Dobos, 1981 ; Parsons, 2014). The impacts of heatwaves on human health are widely documented especially the correlation of heat and mortality and morbidity (Kovats and Hajat, 2008 ; Sheridan et al., 2009). During the 1995 heatwave in central United States of America (USA) more than 1000 people lost their lives, with Chicago being particularly affected (Klinenberg, 2015 ; Palecki et al., 2001). The heatwave that occurred in Western Europe in 2003 resulted in over 71,000 excess deaths (Robine et al., 2008). Heatwaves are increasingly considered as a serious public health threat globally, especially for vulnerable groups (Bassil and Cole, 2010).

Health vulnerability to heatwaves is distributed unequally across and within societies. Especially the elderly and chronically ill are identified as the most susceptible subgroups at risk (Åström et al., 2015). Risks are classified as intrinsic and extrinsic in nature and linked to environmental and social factors. Protective factors identified are social independence, social support, education and community safety, and a working air conditioning (AC) (Bouchama $\underline{e t ~ a l ., ~} 2007$; Williams $\underline{e t}$ $\underline{a l} ., 2013)$. One study revealed that strong bonding networks can potentially exacerbate rather than reduce vulnerability of elderly people (Wolf et al., 2010b). The highest risk of death during a heatwave was associated with being confined to bed, not leaving home daily and being unable to care for oneself (Bouchama et al., 2007). In terms of pre-existing medical conditions, psychiatric illness was the factor most strongly associated with death, followed by cardiovascular illness and pulmonary illness (Bouchama et al., 2007). Similarly another study found that those between 65 and 74 who had a history of chronic pulmonary disease or suffered from a psychiatric disorder were particularly at risk, while for persons over 75 years factors such as living in a single household and being a women were most relevant (Wong et al., 2012). Dysfunctional thermoregulatory mechanisms, chronic dehydration, medications and diseases involving the systems that regulate body temperature are further identified risk factors which render elderly and multi-morbid patients such as diabetics more vulnerable to heat (Worfolk, 2000; Yardley et al., 2013a; Yardley et al., 2013b). Other studies also looked at heatwave vulnerability in nursing and residential homes and criticize the lack of effective heat management which make people in need of care more vulnerable (Brown and Walker, 2008; Gupta et al., 2017; Rest and Hirsch, 2015 ; Skinner et al., 2009). Children due to their higher physiological sensitivity as well as outdoor workers due to their extensive physical exposure are routinely identified as more vulnerable (Bethel and 
Mayrhuber, E.S., Dückers, M.L.A., Wallner, P., Arnberger, A., Allex, B., Wiesbock, L., Wanka, Af Kolland, F., Eder, R., Hutter, H.P., Kutalek, R. Vulnerability to heatwaves and implications for public health interventions - A scoping review. Environmental Research: 2018, 166(10), $42-54$

Harger, 2014; Lucas et al., 2014; Vanos, 2015 ; Xu et al., 2012). For farmworkers and construction workers this may be coupled with low salaries and unfavorable living conditions (Al-Sayyad and Hamadeh, 2014; Chan et al., 2011 ; Chan et al., 2013) and more resources are demanded to protect them (Dutta et al., 2015). Homelessness and being a homeless veteran were also identified as risk factors (Nicolay et al., 2016) as well as belonging to a cultural and linguistic minority group

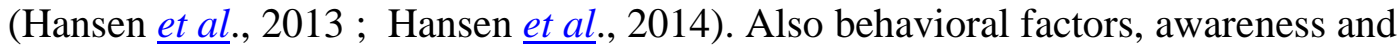
attitudes towards heatwaves were identified as protective or risk factors (Abrahamson et al., 2009; Akompab et al., 2013; Lane et al., 2014; Strengers and Maller, 2011 ; Wanka et al., 2014) as well as social and cultural understandings of comfort and vulnerability (Maller and Strengers, 2011). Some studies also conceptualize vulnerability to heatwaves more broadly in terms of social inequality and deprivation. Accordingly risk is identified as an intersection of poor health, social marginalization and built environmental impediments (Prudent $\underline{e t ~ a l}$., 2016 ; Werg et al., 2013).

Vulnerability to heatwaves is increasingly exacerbated through the Urban Heat Islands (UHI) phenomenon caused by a reduction in latent heat flux and an increase in sensible heat in urban areas as vegetated and evaporating soil surfaces are replaced by relatively impervious low albedo paving and building materials (Imhoff et al., 2010). At the same time there is a growing aging urban population and climate models projecting future heatwaves to become more intense, more frequent and longer lasting in the near future (Meehl and Tebaldi, 2004). The measurable severity of adverse health effects may depend on methodological challenges and data insecurities, as well as the timing of a heatwave, with amplified effects on first seasonal heatwaves (Liss et al., 2017 ; Xu et al ., 2016). The prevention of deaths and mortalities caused by excessive heat events is of public health concern. Interventions, programs and heat health warning systems are increasingly implemented across different countries (Kovats and Hajat, 2008). Today, little is known about their effects as well as the degree to which risk and protective factors (or vulnerability factors) described earlier are addressed by interventions, programs and systems across geographies, and on whose behalf.

This scoping review aims to assess who is targeted by interventions and investigate the effectiveness and efficiency of public health interventions aimed at reducing heatwaves' health impact.

\section{MATERIALS AND METHODS}

A scoping review is particularly suitable for the broad topic of interventions to reduce health vulnerability to heatwaves and their effectiveness. The review is based on the framework by Arksey and O'Malley (2005) and allows for the inclusion of studies with different methodological designs and from varied disciplines. According to the five stages, research questions were identified, relevant studies were located and selected, the data was charted and collated and results were reported (Arksey and O'Malley, 2005). We included methodological advancements to clarify the applied concepts in the research question and redefine search terms (Daudt et al., 2013 ; Levac et al., 2010).

We performed a literature search in PubMed, Web of Science, Scopus, ScienceDirect, Psychinfo and Embase in February and March 2017 to identify relevant studies. The search model had four elements: 1) approaches, interventions 
Mayrhuber, E.S., Dückers, M.L.A., Wallner, P., Arnberger, A., Allex, B., Wiesbock, L., Wanka, Af Kolland, F., Eder, R., Hutter, H.P., Kutalek, R. Vulnerability to heatwaves and implications for public health interventions - A scoping review. Environmental Research: 2018, 166(10), $42-54$

and programs, 2) adverse health effects, 3) heatwaves, and 4) vulnerable populations, adjusting search strings and MeSH terms. Search strings for the first element were composed of keywords used in Bassil and Cole (2010) and further complemented to reach all relevant studies on interventions. A detailed overview including the applied filters (publication date 1995-2017) is provided in Table 1.

\section{[TABLE 1]}

The search generated 1598 potentially relevant studies. The studies were imported into an EndNote library and retrieved items were de-duplicated (Bramer et al., 2016). This resulted in 784 studies for screening. EM first screened the title and abstract of these studies and excluded a total of 698 studies. Then, the full text of the eligible 86 articles was examined, resulting in 23 articles. Five co-authors (AA, BA, MD, PW and RK) double-checked the 86 articles for final inclusion, an $82 \%$ median agreement (range: $75-86 \%$ ) was reached. Mismatched articles were subject to a case by case discussion until a joint decision was reached. For the study selection process see flow diagram in Fig. 1. During the double-check procedure the research questions were further refined and inclusion and exclusion criteria finalized (Levac et al., 2010).

\section{[FIGURE 1]}

\subsection{Inclusion and exclusion criteria}

Studies were included when they analyzed public health interventions to counter adverse health effects of heatwaves in vulnerable populations, and when they analyzed the effectiveness or efficiency of these interventions. Studies were excluded when interventions were not linked to health outcomes (e.g. studies on mitigation measures in urban designs, personal coping behavior, and functional cooling wear) and when full text was not available or when studies were published in a language other than English or German.

Due to the limited number of relevant studies and the scoping review approach, no quality assessment criteria (in terms of stronger or weaker methodologies) was enforced.

\subsection{Charting the data and reporting the results}

The details of studies included in the review are presented in tables. Each publication was first categorized based on the year, location(s) of the intervention and the type of research approach (see Table 2). From each study we extracted data relating to the type of intervention, the specifities it entailed, the target group and the main results of the study; the charted data is included in the appendix Table 3. Data on evaluation of effectiveness and efficiency was also extracted and presented (see separate charts in appendix Table 4 and Table 5). Four co-authors (AA, MD, PW and RK) crosschecked all tables and extracted data for completeness. 
Mayrhuber, E.S., Dückers, M.L.A., Wallner, P., Arnberger, A., Allex, B., Wiesbock, L., Wanka, Af Kolland, F., Eder, R., Hutter, H.P., Kutalek, R. Vulnerability to heatwaves and implications for public health interventions - A scoping review. Environmental Research: 2018, 166(10), $42-54$

\section{[TABLE 2]}

\section{RESULTS}

\subsection{Profile of studies}

The majority of studies were carried out in the United States (US) or Western Europe. The 23 included studies consisted of eight reviews comparing different heat health warning systems and interventions across countries, municipalities or cities (Grewe and Blättner, 2011; Grewe and Pfaffenberger, 2011; Kovats and Ebi, 2006; Lowe et al., 2011; Martinez et al., 2011; Paz et al., 2016). Two reviews dealt exclusively with effectiveness, thereof one structured review included and analyzed 14 studies (Bassil and Cole, 2010) and one systematic literature search included and analyzed 15 studies (Toloo et al., 2013). Five studies were included in both effectiveness reviews (see Table 5). Six studies classified as description studies (Knowlton et al., 2014; Kosatsky et al., 2005; Martin, 2016; Michelozzi et al., 2010;

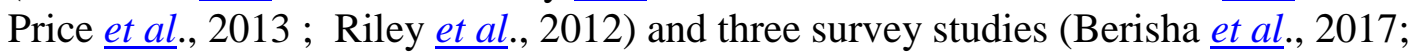
Kunst and Britstra, 2013 ; O'Neill et al., 2010) met the inclusion criteria. Six studies used a qualitative or mixed methods design (Boeckmann, 2016; Bolitho and Miller, 2016; Mees et al., 2015; Paterson et al., 2012; Van Loenhout et al., 2016 ; WhiteNewsome et al., 2014).

The darker the country in Fig. 2 the more studies reported on interventions in the country, scaled up from local region, or city. None of the included studies reported on countries that appear in light grey.

\section{[FIGURE 2]}

\subsection{VULNERABILITY: TARGET GROUPS AND RISK AND PROTECTIVE FACTORS}

\subsubsection{Vulnerable populations}

Public health interventions target different groups in specific locations and address intrinsic as well as extrinsic risk factors. We found interventions implemented on different levels (federal level, state government level, city level, local level) (Bolitho and Miller, 2016; Knowlton et al., 2014; Kosatsky et al., 2005; Martin, 2016; Mees et al., 2015; Michelozzi et al., 2010; Paz et al., 2016; Price et al., 2013; WhiteNewsome et al., 2014) and aiming to reach whole populations or only particular vulnerable groups.

All studies mention age as a major significant intrinsic risk factor to be considered in interventions, due to impaired physiological and behavioral responses to heat (Grewe and Blättner, 2011). Warnings also address individuals with impaired medical status, such as persons suffering from a chronic disease and using specific medication or individuals who are obese or unfit, people with a disability, persons who suffer from mental illnesses or substance abusers (Lowe et al., 2011; Martin, 2016).

Additionally "people in need of, or dependent on care", those who are confined to bed and/or "institutionalized people" as well as their care takers are targeted by interventions (Mees et al., 2015). Risk in institutionalized people is explained by a combination of exposure and susceptibility and limited ability to influence thermal comfort (Grewe and Pfaffenberger, 2011). Young children are also listed, both 
Mayrhuber, E.S., Dückers, M.L.A., Wallner, P., Arnberger, A., Allex, B., Wiesbock, L., Wanka, A Kolland, F., Eder, R., Hutter, H.P., Kutalek, R. Vulnerability to heatwaves and implications for public health interventions - A scoping review. Environmental Research: 2018, 166(10), $42-54$

vulnerable because of weaker thermoregulation and potential higher outdoor exposure (Boeckmann, 2016; Van Loenhout et al., 2016), however, we did not encounter studies on interventions specifically targeting children's' care takers, guardians, or teachers. Some studies considered high risk working and living conditions and individuals who perform heavy physical exercise, outdoor seasonal or constructional workers (Riley et al., 2012), municipal police officers or rickshaw drivers (Knowlton et al., 2014). Interventions also specifically target people living in informal settlements, slums (Knowlton et al., 2014), top floor apartments, in highrise buildings or in row homes (White-Newsome et al., 2014). In some cases interventions tackled social aspects of neighborhood, social networks and notions of security (O'Neill et al., 2010 ; Paz et al., 2016). In two studies homelessness was, for instance, identified as a highly influential extrinsic risk factor (Martin,

2016; Paterson et al., 2012). Other studies report on interventions targeting specific ethnic communities or especially diverse populations (White-Newsome et al., 2014), or defined vulnerability according to multiple criteria: homeless, under-housed, and frail, isolated, seniority, as well as being member of an aboriginal community (Kosatsky et al., 2005 ; Kovats and Ebi, 2006). Considering protective factors, studies mention those without access or capability to run an AC as targeted by interventions (Berisha et al., 2017).

\subsubsection{Detection of risk and protective factors}

Interventions and measures were divided into two types: those to detect and those to influence risk and protective factors. Interventions to detect risk and protective factors include meteorological forecasting, temperature monitoring, developing a robust understanding of the cause-and-effect relationships between thermal environment and health outcomes at population level and any form of surveillance systems (i.e. real-time surveillance of mortality and morbidity, syndromic surveillance of heat related hospital visits during extreme heat alerts) (Kovats and Ebi, 2006; Lowe et al., 2011 ; White-Newsome et al., 2014). Heat monitoring interventions constitute an integral part of every heat health warning system described in the studies. This is to detect what constitutes impeding dangerous hot weather in a specific area and translating it into forecasts and warnings. Additionally we found mapping of vulnerable people and passive and active outreach programs were frequent interventions and measures to detect risk and protective factors (Lowe et al., 2011).

Several cities, such as Paris, France, and Kassel, Germany, installed voluntary registration systems where vulnerable citizens can register themselves (Mees et al., 2015). In Rome and other Italian cities, a registration system operates through records of hospital admissions and general practitioners (GPs), and social workers. Some run a registration of susceptible individuals that uses population registries and other data for identification in the population aged 65 and over (Michelozzi et al., 2010). In Toronto, Canada public health authorities use an advanced modelling tool relying on extensive lists of indicators for exposure, sensitivity and adaptive capacity (Mees et al., 2015 ; Paterson et al., 2012). In Montreal, Canada, local health departments identify vulnerable individuals. This is combined with a door-to-door campaign to identify people suffering from heat and in need of assistance, performed 
Mayrhuber, E.S., Dückers, M.L.A., Wallner, P., Arnberger, A., Allex, B., Wiesbock, L., Wanka, A Kolland, F., Eder, R., Hutter, H.P., Kutalek, R. Vulnerability to heatwaves and implications for public health interventions - A scoping review. Environmental Research: 2018, 166(10), 4254

by municipal partners (Price et al., 2013). Hospitals, nursing homes, GPs and medical staff target registered at-risk subgroups also in preventive activities as well as active surveillance interventions (Michelozzi et al., 2010). Active surveillance of high and very high risk patients in Italy is, for instance, operated through a dedicated telephone line that triggers a network of health and social services in case of an emergency. GPs can actively monitor patients through telephone calls and home visits, modulation in pharmacological treatment, home-based treatments, and special attention towards at-risk patients discharged from hospital, when necessary (Michelozzi et al., 2010). Country comparison reviews describe home outreach visits or phone calls to vulnerable persons (by GPs, social workers or volunteers), evacuation of vulnerable persons from their homes to cooling centers as well as outreach to homeless persons as common interventions incorporated into heat health warning systems (Kovats and Ebi, 2006 ; Lowe et al., 2011). In highly affected US cities outreach programs were adopted in which service providers reach out and visit specific sites and provide direct assistance (White-Newsome et al., 2014). Detroit Homeland Security and Emergency Medics i.e. created a list of people who cannot be moved for heat; similarly in New York City (NYC) a list with most vulnerable clients is regularly updated (White-Newsome et al., 2014). A partnership with the US Postal Service Carrier Alert program exists in NYC and if a person does not pick up mail in three or four days the nearby community based organization is sent to see if the person is well (White-Newsome et al., 2014). Furthermore, the "Notify NYC" program and a partnership with the union of doormen were established (WhiteNewsome et al., 2014) to reach potentially vulnerable people who might not be visible as they may not leave their flats. In Philadelphia home-based outreach is targeted to residents who receive assistance from agencies and NGOs and in Phoenix contact is established through i.e. assisted living facilities and group homes (WhiteNewsome et al., 2014). Philadelphia is a prominent example as it also works with a buddy system, consisting of community volunteers who actively keep an eye on and pay visits to vulnerable citizens and nursing teams paying home visits following calls from the heat-line (Mees et al., 2015). In Japan heat protection information is directly provided to private citizens that have voluntarily registered in the warning distribution list (Martinez et al., 2011). Specific outreach activities such as regular home visits (yogurt and newspaper delivery, trash pick-ups) for elderly during hot spells and distribution of how-to-keep-cool-indoors advice are organized through volunteer networks such as the "Minsei committees" (Boeckmann, 2016; Martinez et al., 2011). In the heat action plan for Ahmedabad, India, vulnerable residents are identified and reached by location, i.e. implementing water tankers in urban slum dwellings or installing electronic temperature displays (Knowlton et al., 2014). Efforts to map vulnerable people as well as map weak spots in inter-organizational capacity through an overview of housing locations and facilities frequently go hand in hand with active outreach activities through established social service networks, or registered people or the general health care systems.

\subsubsection{Influencing risk and protective factors}

The review also points at interventions and measures to influence risk factors (including exposure) and protective factors (including behavior), which aimed for instance at heat exposure reduction. They entailed the allocation and dissemination 
Mayrhuber, E.S., Dückers, M.L.A., Wallner, P., Arnberger, A., Allex, B., Wiesbock, L., Wanka, A Kolland, F., Eder, R., Hutter, H.P., Kutalek, R. Vulnerability to heatwaves and implications for public health interventions - A scoping review. Environmental Research: 2018, 166(10), 4254

of instruments and tools that aid individual cooling of living environment or the body. There are fan and AC distribution programs, subsidy schemes for AC purchase costs and electricity cease disconnection for non-payment (Grewe and Pfaffenberger, 2011; Kovats and Ebi, 2006; Martin, 2016; Mees et al., 2015; White-Newsome et al., 2014). Other measures to reduce heat exposure were protective measures for occupationally highly exposed workers. We encountered exposure reduction interventions and measures that related to the establishment, access and use of cooling centers. Especially in the US, several studies considered moving vulnerable people to cooling centers, either from the street or evacuating them from their homes (Kosatsky et al., 2005; Lowe et al., 2011; White-Newsome et al., 2014). Authors also studied the setting up of cooling centers during heatwaves in cities. Thereto related, some studies reported about provisions to extend opening hours of public AC places and swimming pools, so people had the opportunity to increase time spent in cooler spaces. Specific awareness raising interventions among patients and health care providers also constituted an intervention to influence risk and protective factors. Examples include alerts to hospital emergency rooms and ambulance service and activation of emergency protocols in care, often applied in retirement homes and hospital settings (Grewe and Pfaffenberger, 2011; Kovats and Ebi, 2006; Lowe et al., 2011; Martin, 2016; O'Neill et al., 2010). In terms of health services, the urgency of involvement of institutions and civil society is emphasized - with sufficient resources, capacity, knowledge and specific interventions, including alerts to hospital emergency rooms, ambulance services and activation of emergency protocols in care and retirement homes and hospitals (Kovats and Ebi, 2006). In France, for instance, municipalities and public health services are explicitly instructed to safeguard and monitor medical and nursing care during heatwaves (Grewe and Pfaffenberger, 2011). Also the provision of cool rooms in care institutions and hospitals is a measure to influence heat health vulnerability. Other measures such as informing and training GPs and health care providers in hospitals, elderly care and nursing homes and those in home-care was mentioned to decrease the impact of heatwaves on health. In a concrete institutional care context, it is highlighted that self-initiated seeking of cooler locations may be challenging for persons in need of care with limited mobility or cognitive impairment. Care-takers and treating physicians are seen as logical actors to identify and target individuals who may be at risk during heat periods by choosing measures reducing exposure, such as "situational" nursing and medical measures (Grewe and Pfaffenberger, 2011). The national heat plan for The Netherlands also provides specific cooling measures to be implemented for residents of institutions both at the institutional and the individual level (Kunst and Britstra, 2013). In a study reporting about Canadian city programs to protect public health from the effect of summertime heat, local health centers targeted their vulnerable elderly clients requiring follow-up during heatwaves based on the identification of factors such as dehydration, medications, social isolation and lack of access to a nearby cooling room (Kosatsky et al., 2005).

Lastly, interventions and measures were identified that aimed at informing and instructing people about what they can do themselves to be protected from heat (Boeckmann, 2016). This occurred via media and government communication as well as dissemination of heat advice and cooling centers through leaflets, pamphlets and telephone heat-lines. Promotion of risk management typically points to the 
Mayrhuber, E.S., Dückers, M.L.A., Wallner, P., Arnberger, A., Allex, B., Wiesbock, L., Wanka, Af Kolland, F., Eder, R., Hutter, H.P., Kutalek, R. Vulnerability to heatwaves and implications for public health interventions - A scoping review. Environmental Research: 2018, 166(10), $42-54$

importance of hydration, avoidance of heat exposure and seeking cool places, often accompanied by the recommendation to check upon vulnerable friends and family members (Knowlton et al., 2014). Informing and instructing people also included education and awareness programs though health promoters and peer trainers as it was carried out in California, reaching largely low-wage immigrant, non-union workforces (Riley et al., 2012). Awareness raising and educational campaigns are particularly linked to influencing behavior. Behavioral change advice is of high priority in public health interventions to reduce health vulnerability against heatwaves (Boeckmann, 2016). The emphasis on prevention of heatwave related health impacts is found in several studies:

"Heat stress may be preventable through early warning systems and response plans, meant to trigger behavior of citizens, such as shading windows, drinking water and seeking cooler places" ( Mees et al., 2015)

While some studies specify characteristics and identification of at-risk groups or individuals quite in detail, other studies report little about the implementation of target-group directed interventions and how they identify and reach out to vulnerable groups (Paz et al., 2016). In general, the studies contain information on multiple interventions to detect and influence risk and protective factors. Interventions are not analyzed or measured separately.

\subsection{EFFECTIVENESS AND EFFICIENCY OF INTERVENTIONS}

The majority of studies criticize the lack of strong evidence of effectiveness of interventions and intervention packages such as heat health warning systems. Several studies highlight that evaluations on the effectiveness in reducing heatwave mortality and morbidity, predicting heatwaves, notifying vulnerable populations, and adoption of adaptation advice (associated with communications) are urgently required to inform good practices (Lowe et al., 2011; Mees et al., 2015). Other studies state that a standardized and evidence based best practice for evaluating programs and action plans is urgently required (Michelozzi et al., 2010; Paterson et al., 2012; Paz et al., 2016). Studies reported that heat health warning systems are extremely difficult to evaluate while there is a lack of published information on formal assessments of the effectiveness of the system as a whole or of individual intervention measures (Kovats and Ebi, 2006; O'Neill et al., 2010). In order to be able to evaluate a system, the components and operation have to be known as well as resources used to operate the system (Kovats and Ebi, 2006). Recommendations for additional evaluation criteria are simplicity, acceptability, sensitivity, timeliness, effectiveness of individual response measures and specificity (Kovats and Ebi, 2006). There is also the aspect of implementation linked to effectiveness analyzed in some studies. Implementation barriers were related to shortage of and expertise among personnel (negligence, lack of knowledge), as well as lack of awareness by residents, and the need to respect residents' independence (Kunst and Britstra, 2013). For the study on the educational campaign activities in California it was reported that the socio-political and economic context presented obstacles to the effectiveness of the heat standard and to education as a successful implementation strategy (Riley et 
Mayrhuber, E.S., Dückers, M.L.A., Wallner, P., Arnberger, A., Allex, B., Wiesbock, L., Wanka, Af Kolland, F., Eder, R., Hutter, H.P., Kutalek, R. Vulnerability to heatwaves and implications for public health interventions - A scoping review. Environmental Research: 2018, 166(10), $42-54$

al., 2012). For detailed information on evaluation of effectiveness see Table 4: Evaluation of effectiveness included in the appendix.

Two reviews that were included in this scoping review precisely scrutinized studies which evaluated the effectiveness of public health interventions and heat health warning systems (Bassil and Cole, 2010 ; Toloo et al., 2013). Both reviews differentiate between effectiveness in reducing adverse health outcomes and effectiveness in alerting human response and build the core result part of this chapter, for charted details see Table 5: reviews on effectiveness in the appendix.

We did not detect studies that evaluated the efficiency of public health interventions to reduce the health impact of heatwaves.

\subsubsection{Effectiveness in reducing negative health outcomes}

Studies typically measured effectiveness in reducing heat-related morbidity and mortality through comparing time periods with and without heat health warning systems or response plans in place (Bassil and Cole, 2010 ; Toloo et al., 2013).

Toloo et al. (2013) reviewed studies on effectiveness and included six studies showing that substantially less people died after the implementation of a heat health warning system and one study being inconclusive. Yet, none of the studies were able to establish a causal relationship between the implementation of a system and reduced mortality. All reviewed studies acknowledged other factors that contributed to the reduction in expected mortality, such as overall improvements in health care, better living conditions including use of $\mathrm{AC}$, heightened heat awareness, and the use of insulating building materials.

Bassil and Cole (2010), pointed to a Czech study which reported a decrease in mortality during the 2003 heatwave compared to earlier years. The authors, however, mention that it may be attributed to a greater public awareness of heat warnings (Kyselý and Křŕž, 2008). An often quoted prominent study by Fouillet et al. (2008) supported the effectiveness of heat warnings, finding fewer heat-related mortalities in 2006 after a heat health warning system and its affiliated interventions were implemented. Beyond the factors mentioned above, improvements in public health response, the characteristics of a heatwave, and the upgrading and better performance of the electrical supply were attributed to a respective decreased mortality in studies (Bassil and Cole, 2010). Another example is a study from St. Louis, Missouri, which compared mortality in the 1980 and 1995 heatwave. It reports higher mortality rates in 1980, however, a simulated model suggested that the population was more vulnerable in 1995 despite an increase in AC availability and improved public health response (Smoyer, 1998). This was attributed to an increase in the "frail elderly" population over 74 , rising poverty rates among the general population as well as increased number of persons over 65 years (Bassil and Cole, 2010).

A preliminary evaluation carried out in Italy in 2008 suggested that a reduction in the impact of heat on mortality had occurred since the introduction of a heat health warning system and prevention program (Michelozzi et al., 2010). However, the 
Mayrhuber, E.S., Dückers, M.L.A., Wallner, P., Arnberger, A., Allex, B., Wiesbock, L., Wanka, Af Kolland, F., Eder, R., Hutter, H.P., Kutalek, R. Vulnerability to heatwaves and implications for public health interventions - A scoping review. Environmental Research: 2018, 166(10), $42-54$

potential effectiveness of individual interventions that were included in the heat prevention plans were still not formally evaluated. With reference to other studies, the authors emphasize that alternative explanations cannot be disregarded and more has to be done to improve evaluations (Michelozzi et al., 2010).

In the 2013 review, no study could be detected to measure the potential benefit of a warning system in terms of heat-related morbidity. Considering different ways of measuring, one US study looked at the dispatch of emergency medical services (used as proxy indicator for morbidity), which was reduced by $49-73 \%$ on heatwave days in 1999 with an alert system in place compared to 1995 without a system in place (Weisskopf et al., 2002). An increasing number of studies measured the number of emergency hospital admissions or calls to ambulances during heatwaves that often are reported to have increased (Toloo et al., 2013). However, there are differences between fatal and non-fatal admissions and related causes for admissions and the effectiveness of heat health warning systems in reducing morbidity requires further research (Toloo et al., 2013).

Both effectiveness-reviews included the same single study measuring the costeffectiveness, namely a study which measured the cost-benefits of implementing the hot weather-health watch warning system in Philadelphia, Pennsylvania (Ebi et al., 2004). It concluded that for similar hot days with or without a warning issued during the 1995-1998 period, the excess mortality was reduced by an average of 2.6 lives per day, when a warning was issued. Access mortality was calculated as the difference between observed number of deaths and the underlying trend estimated from prior years. Accordingly, 117 lives were saved over three years for the age group of 65 and over, thereby using an adjusted figure of $\$ 4$ million based on the Environmental Protection Agency's value of statistical life for this age group. In total, the saved lives would have valued $\$ 468$ million in contrast to the cost of running the system of $\$ 210,000$ over the same period (Ebi et al., 2004). It is noted that cost-effectiveness may only partially reflect the full value of a life lost, excluding intangible components such as the intrinsic value of a person to their family or community ( Bassil and Cole, 2010). Kunst and Britstra (2013) recommend in their study that further research should assess the cost-effectiveness of measures aimed at preventing heat-related morbidity and mortality.

Bassil and Cole (2010) contrasted intervention efforts with meteorological factors or reduced susceptibility of the population and concluded that it remained unclear to what extent the mortality and morbidity reduction could be attributed to the intervention. Toloo et al. (2013) also pointed to the evidence of a harvesting effect, especially when several heatwaves occur in one season and discuss the analytical techniques used in the studies comparing the observed and expected mortality or use of emergency medical services between two heat periods (Toloo et al., 2013). Beyond that, the issue of different ranges of various responses and interventions is noted:

"... associating the reduction in mortality (or morbidity) to the effectiveness of HWS (ref. heat warning system) also incorporates the effectiveness of these response programs. Since the type, extent of availability and utilization of these responses 
Mayrhuber, E.S., Dückers, M.L.A., Wallner, P., Arnberger, A., Allex, B., Wiesbock, L., Wanka, Af Kolland, F., Eder, R., Hutter, H.P., Kutalek, R. Vulnerability to heatwaves and implications for public health interventions - A scoping review. Environmental Research: 2018, 166(10), $42-54$

varied from one study to another, we cannot infer which measures were more effective than others." ( Toloo et al., 2013)

Additional to evaluations of effectiveness in reducing mortality and/or morbidity, studies reported internal data collection to further continuously improve heat health warning systems and interventions. For instance, in Philadelphia, Pennsylvania, and Phoenix, Arizona, surveillance of heat-related deaths, emergency dispatches, hospitalizations and hospital discharges during extreme heat events were used to inform future preparedness plans and in Phoenix longitudinal data collection was carried out (White-Newsome et al., 2014). The effectiveness of the heat stroke prevention plan in Japan is monitored through publications of morbidity and mortality data in three out of five provinces, as well as through process indicators (3/5), including ambulance calls and number of service registrants (Martinez et al., 2011). Yet, no formal monitoring and evaluation in terms of outcome or process is carried out.

\subsubsection{Effectiveness in alerting human response}

Studies defining effectiveness in terms of rising public awareness or individual behavioral change measured e.g. if messages actually reached people, if they developed problem awareness, if they reported changes in individual practices or increased use of services (i.e. heat-lines called (Kalkstein, 2002), cooling centers visited, etc.). They typically rely on indirect indicators or are designed as public perception surveys.

One study found, for instance, that front-line workers (those who were involved in operating a warning system as well as those working with vulnerable groups) felt that vulnerable, elderly and socially isolated persons were often not aware of a heat alert being declared (Angus, 2006). Challenges in risk communication and behavior change are also noted in another study, as i.e. public messaging and education for those who are most vulnerable might not reach them as those are isolated and lack strong social networks (Martin, 2016). Furthermore, when considering that the Montreal study showed that from 21 reported heat-related community deaths of people with mental illnesses, of which many lived alone, 14 were contacted $24 \mathrm{~h}$ prior to their death by health care professionals, family members, neighbors and friends (Price et al., 2013) the question arises if active telephone outreach is effective for vulnerable groups.

A postal survey conducted in Portugal after the 2003 heatwave suggested that knowledge of the heat warning was nearly universal (92\%), however, the elderly over 75 and less-educated were less likely to heed advice (Nogueira et al., 2005). According to a French survey, awareness of heat alerts was associated with a relatively high level of change in practice and increased uptake (INPES, 2006). Respondents also reported to increasingly support vulnerable friends and family (73\%), fewer elderly reported having been helped (63\%) and only $14 \%$ asked for help when they felt discomfort. In Phoenix, Arizona, less than $50 \%$ of those over 65 actually reported to have changed their behavior, which means that heat advice did not necessarily translate into action (Kalkstein and Sheridan, 2007). A telephone 
Mayrhuber, E.S., Dückers, M.L.A., Wallner, P., Arnberger, A., Allex, B., Wiesbock, L., Wanka, A Kolland, F., Eder, R., Hutter, H.P., Kutalek, R. Vulnerability to heatwaves and implications for public health interventions - A scoping review. Environmental Research: 2018, 166(10), $42-54$

survey inquiring over 65 year olds across four US cities came to similar results. While the knowledge of warnings was again quite high (90\%), knowledge of details was less well understood and only a few actually changed their practices in response (Sheridan, 2007). This was related to the fact that many respondents did not believe they were at-risk or that the advice applied to them. Beyond that there existed confusion about the differences in risks from ozone and heat and its precautions (Sheridan, 2007). Remarkably, a similar risk perception was found in a recent US study, where only a few elderly recognized their own risk, but identified the heat risk and medical concerns in others (Abrahamson and Raine, 2009). Toloo et al. (2013) refer partially to the same studies and carve out this element of non-susceptible selfperception which makes it less likely to adopt protective behavior (Alberini et al., 2011; Kalkstein and Sheridan, 2007; Sheridan, 2007). A qualitative study by Wolf et al. (2010a, 2010b) interviewing persons aged over 75 in the United Kingdom (UK) learns that participants did not consider themselves as old, or threatened by heat while they identify others of the same age group as vulnerable (Wolf et al., 2010a). Interestingly, in a study on heat perception in people with chronic cardiac and pulmonary disease most of the chronically ill population did perceive themselves to be susceptible to heat and reported implementing preventive actions in response (Kosatsky et al., 2009).

To sum up, studies that investigated behavior and practices suggest that those who perceived themselves to be personally vulnerable were more likely to take protective actions (Abrahamson and Raine, 2009; Alberini et al., 2011; Ibrahim et al., 2012; Kalkstein and Sheridan, 2007; Richard et al., 2011; Semenza et al., 2008; Sheridan, 2007 ; Wolf et al., 2010a). Thus, those potentially at risk did not necessarily consider themselves vulnerable.

Likewise were the effectiveness of cooling centers and access barriers related to perceptions of vulnerability, aspects of practicality, and an unclear understanding of benefits (Berisha et al., 2017). According to Smoyer (1997), many elderly were not taking advantages of cooling centers because "they are only for really poor people" (Smoyer, 1997). In another study similar issues around stigma in using a cooling center were brought up, "it is only for seniors or homeless individuals" (WhiteNewsome et al., 2014). Residents of Baltimore, Maryland, related that they "did not like the idea of going to a cooling center during the day and getting comfortable only to return home where they do not have AC" (Martin, 2016), a perception that is obviously linked to a lack of understanding of the overall benefits of cooling centers. Considering that $78 \%$ of cooling center visitors in another study reported to use the facilities for their primary services rather than to seek refuge from heat (or because they perceived themselves to be at-risk), a focus on upgrading existing social service provision and to better inform potential users appears sensible.

Analyzing the effectiveness of the National Heatwave Plan in the UK, health care providers and staff of regional public health units, social care inspectors and primary care trusts expressed concern over whether information actually reached vulnerable people (Johnson and Bickler, 2007). Ibrahim et al. (2012)discovered that health care providers were aware of protective factors regarding heat exposure but were less familiar with basic principles of thermoregulation. An evaluation of the Dutch 
Mayrhuber, E.S., Dückers, M.L.A., Wallner, P., Arnberger, A., Allex, B., Wiesbock, L., Wanka, Af Kolland, F., Eder, R., Hutter, H.P., Kutalek, R. Vulnerability to heatwaves and implications for public health interventions - A scoping review. Environmental Research: 2018, 166(10), $42-54$

national heat plan among long-term care institutions in Amsterdam identified barriers relating to shortage of and expertise among personnel, and residents' independence (Kunst and Britstra, 2013). These factors all play a role considering the effectiveness of interventions.

In line with existing publications, Boeckmann (2016) suggested to use indicators such as media uptake of warning messages. However, the phenomenon of message fatigue by the general public as well as the media can be a barrier during long heat periods (Martin, 2016). Behavioral advice during heatwave includes often universal tips for the general population and specific tips for at risk groups (e.g. multi-morbid elderly who take particular medications). For vulnerable groups who are in need of care professional monitoring also in term of liquid and electrolyte intake is emphasized as detrimental (Grewe and Pfaffenberger, 2011).

\section{DISCUSSION}

The primary objective of this review was to assess how vulnerable groups are identified and reached in heat health interventions, and to understand the effectiveness and efficiency of those interventions that are published in peerreviewed journals.

Most public health interventions target both, the general population and vulnerable groups. Vulnerability is approached based on intrinsic and extrinsic risk factors, and it is primarily defined in terms of age. Other criteria are medical condition and dependency on care. Beyond individual criteria, circumstances such as heavy duty and outdoor occupational exposure are mentioned, which render people more vulnerable to health effects of heatwaves. Also people living in poorly isolated or illprotective accommodations (e.g. top floors in buildings, row homes, slums) are targeted. Furthermore, public health interventions also identify deprived people in terms of socio-economic status, i.e. homeless persons and indigenous minorities. The definition of target groups and the involvement of those at risk is linked to past heatwave experiences and the analysis of mortality data.

Interventions were divided into two types, 1) interventions to detect and 2) interventions to influence risk and protective factors. The former include: monitoring systems, exposure modelling, mapping of vulnerable people and local interorganizational capacity as well as outreach programs; the latter include: heat exposure reduction measures which also entails awareness raising and educating patients as well as health care providers about protective heat behavior. Behavioral change advice is given high priority in public health interventions. However, studies provide merely descriptions on heat advice ("stay hydrated", "avoid heat", "check on vulnerable people in your social network") but the mechanisms of how exactly behavior can be changed and what models could be used largely remain unexplained.

In the majority of the 23 included studies we found that interventions generally entail packages - which is logical because a "learning systems" or "system resilience" approach would include a combination of "prevention, detection, mitigation and

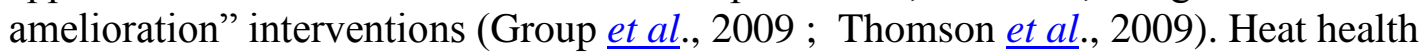


Mayrhuber, E.S., Dückers, M.L.A., Wallner, P., Arnberger, A., Allex, B., Wiesbock, L., Wanka, A Kolland, F., Eder, R., Hutter, H.P., Kutalek, R. Vulnerability to heatwaves and implications for public health interventions - A scoping review. Environmental Research: 2018, 166(10), 4254

warning systems and heat action plans implement a whole set of intervention activities aiming at detecting and influencing primarily extrinsic risk factors. We found public health interventions to draw upon monitoring and mapping of vulnerable people and enhancing weak spots in local inter-organizational capacity to detect but also prevent risks. Mitigation of risk, suffering and adverse health effects is approached by interventions such as active outreach programs to vulnerable people, exposure reduction through distribution of fans, AC, etc., setting up cooling centers and evacuating people. The results show intervention barriers, such as the variety and intersection of different risk factors that renders a person being at risk, the self-perception of those at risk, and overall ideas about interventions, e.g. cooling centers and how they are perceived as beneficial or not.

The research on effectiveness of public health interventions to reduce the potential influence of heatwaves on health is valuable but modesty is appropriate. The majority of studies criticized the lack of strong evidence of effectiveness. At the same time, we found several studies claiming an absence of standardized and evidence based best practice for evaluating interventions and programs to counter heat health effects (White-Newsome et al., 2014). Effectiveness was either measured as reduced mortality and morbidity or analyzed as alerting human response and an overall effectiveness of interventions was found plausible (Bassil and Cole, 2010 ; Toloo et al., 2013). One particular methodological challenge was to proof to what extent the reduction in mortality and morbidity could be attributed to the particular intervention.

Many interventions were aimed at encouraging behavioral change. Eventually, their effectiveness is likely to depend on the motivation (awareness of own vulnerability, intention to adhere), capability (physical and mental conditions, literacy, skills and knowledge) and opportunity (actual access to services and proposed solutions, financial means to make investment) of people (Michie et al., 2011). Such behavioral factors are not worked out in detail in any of the included studies and remain unspecified. Interventions that included education and awareness measures were frequently deployed and linked to influencing behavior. Adequate behavioral advice is, however, complex because it has to match people's risk- and self-perception and experience, which remains under-researched (Singer et al., 2016).

Based on the included studies we identified the most common linear assumptions about behavior. First, that informing people about the danger of heat and particular risks will actually make them aware and adapt their behavior according to advice. Second, at-risk individuals recognize their own vulnerability and therefore will feel concerned by heat alerts and heat messaging. Third, benefits of visiting cooling centers and other heat advice behavior are commonly understood and taken seriously. Fourth, care-takers of vulnerable groups possess the (infrastructural and human resource) capacity to intensify care provision during heatwaves and are sufficiently trained in thermoregulation and possible heat reduction measures. Such assumptions may be problematic as they determine the actual effect of interventions and how vulnerable persons and groups may be reached. With effective promotion and communication of healthy behavior being a contested field of public health research (Kreslake et al., 2016) this is an important finding. In terms of usage 
Mayrhuber, E.S., Dückers, M.L.A., Wallner, P., Arnberger, A., Allex, B., Wiesbock, L., Wanka, A Kolland, F., Eder, R., Hutter, H.P., Kutalek, R. Vulnerability to heatwaves and implications for public health interventions - A scoping review. Environmental Research: 2018, 166(10), 4254

behavior, the case of cooling centers in Arizona was remarkable. It shows that vulnerable people did not believe high summer temperatures could put their health at risk and $78 \%$ of cooling center visitors visited the place to use primary services provided rather than to seek refuge from heat (Berisha et al., 2017). This points to the argument that existing social service facilities should be strengthened in order to reach vulnerable people and protect them from heatwave health risks. The question also arises in how far heat advice is adequate and practicable for the diverse groups of people. A study on the 1995 heatwave in Chicago found i.e. that many affected elderly did not open the window or seek cooling during night times due to security reasons (Klinenberg, 2015).

Challenges for evaluating effectiveness are, to begin with, meteorological in nature, as excessive heat events vary over time and affect populations differently, levels of acclimatization may change and alternative explanations cannot be disregarded (Bassil and Cole, 2010; Toloo et al., 2013). For instance, there is uncertainty to what extent mortality reduction can in fact be solely attributed to a heat health warning system or a particular intervention. Beyond that, an assessment of the effectiveness of intervention can be hindered by the short time frame in which systems are implemented and the limited availability of data (Bassil and Cole, 2010 ; Toloo et al., 2013). In order to link changes at the level of individuals to particular interventions, it is necessary to resolve methodological issues linked to measuring these changes (e.g. changes in drinking and cooling behavior or in perceived benefits, motivation and knowledge to adhere to guidelines) whilst taking into account the degree to which measures are useful in a particular context (Abrahamson et al., 2009; Martin, 2016).

Since we found little information on effectiveness, no information on efficiency and only one study on cost-effectiveness (Fouillet et al., 2008), our review can only produce limited conclusions concerning preferred interventions in different context, the output/input ratio of interventions and the effect of intervention in relation to its costs for policy- and decision making. This scoping review shows that the effectiveness of public health interventions which mostly consist of entangled packages is plausible. We found limited published evidence on evaluation of environmental health interventions against heat, one study also points to the problem of under-investment in program and policy implementation (Bassil and Cole, 2010). In order to adopt an adequate intervention to respond to the mounting health risks due to heatwaves we believe the outlined results and synthesized analysis provide an essential knowledge base to draw from. We utilized a diverse data set that allowed us to map out applied terminology, underlying (behavioral) assumptions, analyze challenges in evaluations, and contrast findings. Still, more research is required on components of effectiveness as well as particular measures within an intervention, to understand outcomes in relation to mechanisms in their particular contexts (Pawson et al., 2005 ; Pawson and Tilley, 1997), especially when it comes to influencing behavior of more or less vulnerable target populations (Michie et al., 2011).

Finally, we must emphasize the existence of a major research gap in terms of equity evaluations. We know very little about how fairly services are distributed among various target groups (Waters et al., 2006). 
Mayrhuber, E.S., Dückers, M.L.A., Wallner, P., Arnberger, A., Allex, B., Wiesbock, L., Wanka, Af Kolland, F., Eder, R., Hutter, H.P., Kutalek, R. Vulnerability to heatwaves and implications for public health interventions - A scoping review. Environmental Research: 2018, 166(10), $42-54$

\section{LIMITATIONS}

The methodological decision to use scientific literature data bases had the implication that studies from countries with a strong scientific community and a good tradition in publishing in peer-reviewed journals were dominant in this review (see Fig. 2: World map). The authors realize that not all interventions are published in peer-reviewed journals and selected published studies are not automatically representative for all interventions that may be applied in different countries. Also, the time dimension of studies that are included in the review and social and political contexts might have changed considerably in the last twenty years.

Like in many literature reviews we cannot rule out the possibility that we missed relevant publications and potentially relevant information from research in other languages. We recommend caution in the cross-national and cross-cultural generalizability of findings from particular study contexts and point to considerations of cultural and socio-economic characteristics of societies, including health care systems and roles and possibilities of stakeholders at different levels, when planning and implementing public health interventions.

\section{CONCLUSIONS}

Public health interventions aim to reduce heat vulnerability through detecting and influencing risk and protective factors in the general population and in particular vulnerable groups. Interventions are mostly studied in packages that are impossible to disentangle and probably should not be disentangled because they strengthen each other. At the same time, this challenges the evaluation of effectiveness and efficiency, and as a result, as long as not resolved, leaves policymakers in a lack of clarity about the most optimal combination of measures to implement in response to heat waves. Studies find that most of the effects reported in terms of mortality and morbidity are positive but strong evidence is lacking. Considering the synthesized results from this scoping review, multifaceted action in line with the discussed interventions and measures is advisable in the context of heatwave interventions. Policymakers as well as funding institutions can use this scoping review to guide decision making. Implementation barriers must be understood within their social, political, economic and geographical context. In order to formulate guidance for policymakers we need to strengthen the evidence on interventions and understand better the components of heat health interventions and functioning of behavioral factors.

\section{ACKNOWLEDGEMENTS}

The authors would like to thank Jonna Lind for her assistance with the literature search.

ACKNOWLEDGEMENTS

\section{Funding}


Mayrhuber, E.S., Dückers, M.L.A., Wallner, P., Arnberger, A., Allex, B., Wiesbock, L., Wanka, A/s Kolland, F., Eder, R., Hutter, H.P., Kutalek, R. Vulnerability to heatwaves and implications for public health interventions - A scoping review. Environmental Research: 2018, 166(10), $42-54$

This work was supported by the Climate and Energy Fund and was carried out within the framework of the 5th Call of the Austrian Climate Research Program 2013 (Grant no. KR13AC6K11022).

\section{Declarations of interest}

None.

APPENDIX A. SUPPLEMENTARY MATERIAL

\section{REFERENCES}

Abrahamson, V., Raine, R., 2009. Health and social care responses to the department of health heatwave plan dagger. J. Public Health 31, 478-489.

Abrahamson, V., et al., 2009. Perceptions of heatwave risks to health: interview-based study of older people in London and Norwich, UK. J. Public Health 31, 119-126.

Akompab, D.A., et al., 2013. Engaging stakeholders in an adaptation process: governance and institutional arrangements in heat-health policy development in Adelaide, Australia. Mitig. Adapt. Strateg. Glob. Change 18, 1001-1018.

Al-Sayyad, A.S., Hamadeh, R.R., 2014. The burden of climate-related conditions among laborers at Al-Razi health centre, Bahrain. J. Bahrain Med. Soc. 25, 5-8.

Alberini, A., et al., 2011. Individual and public-program adaptation: coping with heat waves in five cities in Canada. Int. J. Environ. Res. Public Health 8, 4679-4701.

Angus, J., 2006. An Evaluation of Toronto's Heat Watch Warning System. ProQuest, Toronto, ON, Canada.

Arksey, H., O'Malley, L., 2005. Scoping studies: towards a methodological framework. Int. J. Soc. Res. Methodol. 8, 19-32.

Åström, D.O., et al., 2015. The effect of heat waves on mortality in susceptible groups: a cohort study of a mediterranean and a northern European City. Environ. Health 14, 30.

Bassil, K.L., Cole, D.C., 2010. Effectiveness of public health interventions in reducing morbidity and mortality during heat episodes: a structured review. Int. J. Environ. Res. Public Health 7, 991-1001.

Berisha, V., et al., 2017. Assessing adaptation strategies for extreme heat: a public health evaluation of cooling centers in Maricopa County, Arizona. Weather Clim. Soc. 9, 71-80.

Bethel, J.W., Harger, R., 2014. Heat-related illness among Oregon farmworkers. Int. J. Environ. Res. Public Health 11, 9273-9285.

Boeckmann, M., 2016. Exploring the health context: a qualitative study of local heat and climate change adaptation in Japan. Geoforum 73, 1-5.

Bolitho, A., Miller, F., 2016. Heat as emergency, heat as chronic stress: policy and institutional responses to vulnerability to extreme heat. Local Environ. 1-17.

Bouchama, A., et al., 2007. Prognostic factors in heat wave-related deaths: a metaanalysis. Arch. Intern. Med. 167, 2170-2176.

Bramer, W.M., et al., 2016. De-duplication of database search results for systematic reviews in EndNote. J. Med. Libr. Assoc.: Jmla. 104, 240.

Brown, S., Walker, G., 2008. Understanding heat wave vulnerability in nursing and residential homes. Build. Res. Inf. 36, 363-372.

Chan, A.P.C., et al., 2011. A research framework for assessing the effects of heat stress on construction workers. In: Proceedings of the ISEC. 2011 - 6th International Structural Engineering and Construction Conference: Modern Methods and Advances in Structural Engineering and Construction, pp. 485-489.

Chan, A.P.C., et al., 2013. Using the thermal work limit as an environmental determinant of heat stress for construction workers. J. Manag. Eng. 29, 414-423.

Daudt, H.M., et al., 2013. Enhancing the scoping study methodology: a large, interprofessional team's experience with Arksey and O'Malley's framework. BMC Med. Res. Methodol. 13, 48. 
Mayrhuber, E.S., Dückers, M.L.A., Wallner, P., Arnberger, A., Allex, B., Wiesbock, L., Wanka, A/s Kolland, F., Eder, R., Hutter, H.P., Kutalek, R. Vulnerability to heatwaves and implications for public health interventions - A scoping review. Environmental Research: 2018, 166(10), $42-54$

Dukes-Dobos, F.N., 1981. Hazards of heat exposure: a review. Scand. J. Work Environ. Health 73-83.

Dutta, P., et al., 2015. Perceived heat stress and health effects on construction workers. Indian J. Occup. Environ. Med. 19, 151-158.

Ebi, K.L., et al., 2004. Heat watch/warning systems save lives: estimated costs and benefits for Philadelphia 1995-98. Bull. Am. Meteorol. Soc. 85, 1067-1073.

Fouillet, A., et al., 2008. Has the impact of heat waves on mortality changed in France since the European heat wave of summer 2003? A study of the 2006 heat wave. Int. J. Epidemiol. 37, 309-317.

Grewe, H.A., Blättner, B., 2011. Heat-health action plans in Europe: strategies for combating the health consequences of extreme weather events. Pravent. Gesundh. 6, 158-163.

Grewe, H.A., Pfaffenberger, D., 2011. Prevention of heat-related health threats in nursing homes for the elderly. Pravent. Gesundh. 6, 192-198.

Group, W.A.F.P.S.D., et al., 2009. Towards an International classification for patient safety: the conceptual framework. Int. J. Qual. Health Care 21, 2-8.

Gupta, R., et al., 2017. Overheating in care settings: magnitude, causes, preparedness and remedies. Build. Res. Inf. 45, 83-101.

Hansen, A., et al., 2013. Vulnerability to extreme heat and climate change: is ethnicity a factor? Glob. Health Action. 6, 21364.

Hansen, A., et al., 2014. Extreme heat and cultural and linguistic minorities in Australia: perceptions of stakeholders. BMC Public Health 14, 550.

Ibrahim, J.E., et al., 2012. Minimising harm from heatwaves: a survey of awareness, knowledge, and practices of health professionals and care providers in Victoria, Australia. Int. J. Public Health 57, 297-304.

Imhoff, M.L., et al., 2010. Remote sensing of the urban heat island effect across biomes in the continental USA. Remote Sens. Environ. 114, 504-513.

INPES, I.N.d.P.e.d.E.p.I.S., 2006. Bilan de la vague de chaleur 2006 et actions nouvelles pour lutter contre une canicule. online (link default). Johnson, S., Bickler, G., 2007. Evaluation of the department of health national heatwave plan. Health Prot. Agency 1-16.

Kalkstein, A.J., Sheridan, S.C., 2007. The social impacts of the heat-health watch/ warning system in Phoenix, Arizona: assessing the perceived risk and response of the public. Int. J. Biometeorol. 52, 43-55.

Kalkstein, L.S., 2002. Description of our heat/health watch-warning systems: their nature and extent, and required resources. cCASh Workshop Vulnerability Therm. Stress. 5-7.

Klinenberg, E., 2015. Heat Wave: A Social Autopsy of Disaster in Chicago. University of Chicago Press, Chicago, London.

Knowlton, K., et al., 2014. Development and implementation of South Asia's first heathealth action plan in Ahmedabad (Gujarat, India). Int J. Environ. Res Public Health 11, 34733492.

Kosatsky, T., et al., 2009. Heat awareness and response among Montreal residents with chronic cardiac and pulmonary disease. Can. J. Public Health 100, 237-240.

Kosatsky, T., et al., 2005. How Toronto and Montreal (Canada) respond to heat. Extrem. Weather Events Public Health Responses 167-171.

Kovats, R.S., Ebi, K.L., 2006. Heatwaves and public health in Europe. Eur. J. Public Health 16, 592-599.

Kovats, R.S., Hajat, S., 2008. Heat stress and public health: a critical review. Annu. Rev. Public Health 29, 41-55.

Kreslake, J.M., et al., 2016. Developing effective communication materials on the health effects of climate change for vulnerable groups: a mixed methods study. BMC Public Health 16.

Kunst, A.E., Britstra, R., 2013. Implementation evaluation of the Dutch national heat plan among long-term care institutions in Amsterdam: a cross-sectional study. BMC Health Serv. Res. 13, 135.

Kyselý, J., Kř́ž, B., 2008. Decreased impacts of the 2003 heat waves on mortality in the Czech Republic: an improved response? Int. J. Biometeorol. 52, 733-745.

Lane, K., et al., 2014. Extreme heat awareness and protective behaviors in New York City. J. Urban Health 91, 403-414.

Levac, D., et al., 2010. Scoping studies: advancing the methodology. Implement. Sci. 5, 69. 
Mayrhuber, E.S., Dückers, M.L.A., Wallner, P., Arnberger, A., Allex, B., Wiesbock, L., Wanka, A/s Kolland, F., Eder, R., Hutter, H.P., Kutalek, R. Vulnerability to heatwaves and implications for public health interventions - A scoping review. Environmental Research: 2018, 166(10), $42-54$

Liss, A., et al., 2017. Heat-related hospitalizations in older adults: an amplified effect of the first seasonal heatwave. Sci. Rep. 7.

Lowe, D., et al., 2011. Heatwave early warning systems and adaptation advice to reduce human health consequences of heatwaves. Int. J. Environ. Res. Public Health 8, 46234648.

Lucas, R.A.I., et al., 2014. Excessive occupational heat exposure: a significant ergonomic challenge and health risk for current and future workers. Extrem. Physiol. Med. 3.

Maller, C.J., Strengers, Y., 2011. Housing, heat stress and health in a changing climate: promoting the adaptive capacity of vulnerable households, a suggested way forward. Health Promot. Int. 26, 492-498.

E.A.-S. Mayrhuber et al. Environmental Research 166 (2018) 42-54 53

Martin, J.L., 2016. Responding to the effects of extreme heat: baltimore city's code red program. Health Secur. 14, 71-77.

Martinez, G.S., et al., 2011. Local heat stroke prevention plans in Japan: characteristics and elements for public health adaptation to climate change. Int. J. Environ. Res. Public Health 8, 4563-4581.

Meehl, G.A., Tebaldi, C., 2004. More intense, more frequent, and longer lasting heat waves in the 21st century. Science 305, 994-997.

Mees, H.L.P., et al., 2015. "Cool" governance of a "hot" climate issue: public and private responsibilities for the protection of vulnerable citizens against extreme heat. Reg. Environ. Change 15, 1065-1079.

Michelozzi, P., et al., 2010. Surveillance of summer mortality and preparedness to reduce the health impact of heat waves in Italy. Int. J. Environ. Res. Public Health 7, 2256-2273.

Michie, S., et al., 2011. The behaviour change wheel: a new method for characterising and designing behaviour change interventions. Implement. Sci. 6, 42.

Nicolay, M., et al., 2016. A study of heat related illness preparedness in homeless veterans Int. J. Disaster Risk Reduct. 18, 72-74.

Nogueira, P.J., et al., 2005. Comportamentos das familias portuguesas em epocas de calor e durante a onda de calor de Agosto de 2003. Rev. Port. Saúde Pública. 23, 5-20.

O'Neill, M.S., et al., 2010. US local action on heat and health: are we prepared for climate change? Int. J. Public Health 55, 105-112.

Palecki, M.A., et al., 2001. The nature and impacts of the July 1999 heat wave in the midwestern United States: learning from the lessons of 1995. Bull. Am. Meteorol. Soc. 82, 1353-1367.

Parsons, K., 2014. Human Thermal Environments: The Effects of Hot, Moderate, and Cold Environments on Human Health, Comfort, and Performance. CRC Press, Boca Raton. Paterson, J.A., et al., 2012. Adaptation to climate change in the Ontario public health sector. BMC Public Health 12, 12.

Pawson, R., et al., 2005. Realist review-a new method of systematic review designed for complex policy interventions. J. Health Serv. Res. Policy 10, 21-34.

Pawson, R., Tilley, N., 1997. Realist evaluation. Changes. Paz, S., et al., 2016. Health aspects of climate change in cities with mediterranean climate, and local adaptation plans. Int. J. Environ. Res. Public Health 13, 438.

Price, K., et al., 2013. Implementation of the Montreal heat response plan during the 2010 heat wave. Can. J. Public Health 104, e96-e100.

Prudent, N., et al., 2016. Assessing climate change and health vulnerability at the local level: Travis County, Texas. Disasters 40, 740-752.

Rest, K.D., Hirsch, P., 2015. Supporting urban home health care in daily business and times of Disasters. Ifac Pap. 48, 686-691.

Richard, L., et al., 2011. Correlates of hot day air-conditioning use among middle-aged and older adults with chronic heart and lung diseases: the role of health beliefs and cues to action. Health Educ. Res. 26, 77-88.

Riley, K., et al., 2012. From agricultural fields to urban asphalt: the role of worker education to promote California's heat illness prevention standard. New Solut.: J. Environ. Occup. Health Policy.: NS 22, 297-323.

Robine, J.-M., et al., 2008. Death toll exceeded 70,000 in Europe during the summer of 2003. Comptes Rendus Biol. 331, 171-178. 
Mayrhuber, E.S., Dückers, M.L.A., Wallner, P., Arnberger, A., Allex, B., Wiesbock, L., Wanka, A/s Kolland, F., Eder, R., Hutter, H.P., Kutalek, R. Vulnerability to heatwaves and implications for public health interventions - A scoping review. Environmental Research: 2018, 166(10), $42-54$

Semenza, J.C., et al., 2008. Public perception and behavior change in relationship to hot weather and air pollution. Environ. Res. 107, 401-411.

Sheridan, S.C., 2007. A survey of public perception and response to heat warnings across four North American cities: an evaluation of municipal effectiveness. Int. J. Biometeorol. 52, 3-15.

Sheridan, S.C., et al., 2009. Trends in heat-related mortality in the United States, 19752004. Nat. Hazards 50, 145-160.

Singer, M., et al., 2016. "I Feel Suffocated:" understandings of climate change in an inner city heat Island. Med. Anthropol. 35, 453-463.

Skinner, M.W., et al., 2009. Neither rain nor hail nor sleet nor snow: provider perspectives on

the challenges of weather for home and community care. Soci. Sci. Med. 68, 682-688.

Smoyer, K., 1997. Environmental Risk Factors in Heat Wave Mortality in St. Louis (Ph.D.

Thesis). University of Minnesota, Minneapolis, MN, pp. 326.

Smoyer, K.E., 1998. A comparative analysis of heat waves and associated mortality in St.

Louis, Missouri--1980 and 1995. Int. J. Biometeorol. 42, 44-50.

Strengers, Y., Maller, C., 2011. Integrating health, housing and energy policies: social practices of cooling. Build. Res. Inf. 39, 154-168.

Thomson, R., et al., 2009. Towards an international classification for patient safety: a Delphi survey. Int. J. Qual. Health Care 21, 9-17.

Toloo, G., et al., 2013. Evaluating the effectiveness of heat warning systems: systematic review of epidemiological evidence. Int. J. Public Health 58, 667-681.

Van Loenhout, J.A.F., et al., 2016. Stakeholders' perception on national heatwave plans and their local implementation in belgium and the Netherlands. Int. J. Environ. Res. Public Health 13 (11) (no pagination).

Vanos, J.K., 2015. Children's health and vulnerability in outdoor microclimates: a comprehensive review. Environ. Int. 76, 1-15.

Wanka, A., et al., 2014. The challenges posed by climate change to successful ageing. $Z$. Gerontol. Geriatr. 47, 468-474.

Waters, E., et al., 2006. Evaluating the effectiveness of public health interventions: the role and activities of the Cochrane collaboration. J. Epidemiol. Community Health 60, 285-289.

Weisskopf, M.G., et al., 2002. Heat wave morbidity and mortality, Milwaukee, Wis, 1999 vs 1995: an improved response? Am. J. Public Health 92, 830-833.

Werg, J., et al., 2013. Assessing social capacity and vulnerability of private households to natural hazards - integrating psychological and governance factors. Nat. Hazards Earth Syst. Sci. 13, 1613-1628.

White-Newsome, J.L., et al., 2014. Strategies to reduce the harmful effects of extreme heat events: a four-city study. Int. J. Environ. Res. Public Health 11, 1960-1988.

Williams, S., et al., 2013. Extreme heat and health: perspectives from health service providers in rural and remote communities in South Australia. Int. J. Environ. Res. Public Health 10, 5565-5583.

Wolf, J., et al., 2010a. Heat waves and cold spells: an analysis of policy response and perceptions of vulnerable populations in the UK. Environ. Plan. A 42, 2721-2734.

Wolf, J., et al., 2010b. Social capital, individual responses to heat waves and climate change adaptation: an empirical study of two UK cities. Glob. Environ. Change-Hum. Policy Dimens. 20, 44-52.

Wong, K.F.V., et al., 2012. Heat Island Effect Aggravates Mortality. Proceedings of the Asme International Mechanical Engineering Congress and Exposition, 2011, Vol 4, Pts a and B, pp. 271-285.

Worfolk, J.B., 2000. Heat waves: their impact on the health of elders. Geriatr. Nurs. 21, 70 77.

Xu, X.C., et al., 2016. Impact of high temperature on the mortality in summer of Wuhan, China. Environ. Earth Sci. 75, 9.

Xu, Z., et al., 2012. Impact of ambient temperature on children's health: a systematic review. Environ. Res. 117, 120-131.

Yardley, J.E., et al., 2013a. Is whole-body thermoregulatory function impaired in type 1 diabetes mellitus? Curr. Diabetes Rev. 9, 126-136.

Yardley, J.E., et al., 2013b. Do heat events pose a greater health risk for individuals with type 2 diabetes? Diabetes Technol. Ther. 15, 520-529. 
Mayrhuber, E.S., Dückers, M.L.A., Wallner, P., Arnberger, A., Allex, B., Wiesbock, L., Wanka, A Kolland, F., Eder, R., Hutter, H.P., Kutalek, R. Vulnerability to heatwaves and implications for public health interventions - A scoping review. Environmental Research: 2018, 166(10), 4254

E.A.-S. Mayrhuber et al. Environmental Research 166 (2018) 42-54 54

TABLES

Table 1. : Databases, search models and hits.

\begin{tabular}{|c|c|c|c|c|}
\hline Database & \multicolumn{2}{|l|}{ Query } & $\begin{array}{l}\text { Hits (incl. } \\
\text { duplicate } \\
\text { s) }\end{array}$ & $\begin{array}{c}\text { Hits } \\
\text { (excl. } \\
\text { duplicat } \\
\text { es) }\end{array}$ \\
\hline PubMed & $\begin{array}{l}\text { Search measure*[tiab] OR polic*[tiab] OR } \\
\text { intervention*[tiab] OR plan[tiab] OR plans[tiab] OR } \\
\text { program*[tiab] OR response[tiab] OR evaluat*[tiab] } \\
\text { OR warning*[tiab] OR alert*[tiab] OR watch[tiab] OR } \\
\text { "public health response"[tiab] OR prevention[tiab] OR } \\
\text { preparedness[tiab] OR strateg*[tiab] OR "risk } \\
\text { management"[tiab] OR "disaster management"[tiab] } \\
\text { OR "disaster planning"[tiab] OR "emergency } \\
\text { management"[tiab] OR "relief planning"[tiab] OR } \\
\text { adaptation[tiab] OR adaption[tiab] OR approach*[tiab] } \\
\text { OR "Disaster Planning"[Mesh] AND health[tiab] OR } \\
\text { "heat related illness*"[tiab] OR "Heat Stress } \\
\text { Disorder*"[tiab] OR "Heat Stress Syndrome*"[tiab] } \\
\text { OR "Heat Cramp*"[tiab] OR heatstroke*[tiab] OR } \\
\text { "heat strok*"[tiab] OR sunstroke*[tiab] OR "Heat } \\
\text { Exhaustion"[tiab] OR "Heat Prostration"[tiab] OR } \\
\text { "Heat Collapse"[tiab] OR "heat related risk*"[tiab] OR } \\
\text { morbidity[tiab] OR mortality[tiab] OR "Heat Stress } \\
\text { Disorders"[Mesh] AND "heat wave*"[tiab] OR } \\
\text { heatwave*[tiab] OR "extreme heat*"[tiab] OR "hot } \\
\text { temperature*"[tiab] OR "extreme heat"[Mesh] OR "hot } \\
\text { temperature"[MeSH] OR ((hot[tiab] OR heat[tiab]) } \\
\text { AND (climate[MeSH] OR Heat[MeSH])) AND } \\
\text { vulnerab*[tiab] OR underserved[tiab] OR "Sensitive } \\
\text { Population*"[tiab] OR "Disadvantaged"[tiab] OR } \\
\text { "Underserved Population*"[tiab] OR "Underserved } \\
\text { Patient*"[tiab] OR "Vulnerable Populations"[Mesh] }\end{array}$ & $\mid$\begin{tabular}{||l|} 
Filter: Publication \\
date from \\
1995/01/01- \\
2030/12/31Filter: \\
NOT \\
(animals[mh] \\
NOT \\
humans[mh])
\end{tabular} & $\mid \begin{array}{l}|| \\
188\end{array}$ & 174 \\
\hline $\begin{array}{l}\text { Web of } \\
\text { Science }\end{array}$ & $\begin{array}{l}\text { TOPIC: (measure* OR polic* OR intervention* OR } \\
\text { plan OR plans OR program* OR response OR evaluat* } \\
\text { OR warning* OR alert* OR watch OR "public health } \\
\text { response" OR prevention OR preparedness OR strateg* } \\
\text { OR "risk management" OR "disaster management" OR } \\
\text { "disaster planning" OR "emergency management" OR } \\
\text { "relief planning" OR adaptation OR adaption OR } \\
\text { approach*) ANDTOPIC: (health OR "heat related } \\
\text { illness*" OR "Heat Stress Disorder*" OR "Heat Stress } \\
\text { Syndrome*" OR "Heat Cramp*" OR heatstroke* OR } \\
\text { "heat strok*" OR sunstroke* OR "Heat Exhaustion" } \\
\text { OR "Heat Prostration" OR "Heat Collapse" OR "heat } \\
\text { related risk*" OR morbidity OR mortality) } \\
\text { ANDTOPIC: ("heat wave*" OR heatwave* OR } \\
\text { "extreme heat*" OR "hot temperature*") ANDTOPIC: } \\
\text { (vulnerab* OR underserved OR "Sensitive }\end{array}$ & \begin{tabular}{||l} 
Timespan: 1995- \\
2017. Indexes: \\
SCI- \\
EXPANDED, \\
SSCI, A\&HCI, \\
CPCI-S, CPCI- \\
SSH, ESCI.
\end{tabular} & 352 & 216 \\
\hline
\end{tabular}


Mayrhuber, E.S., Dückers, M.L.A., Wallner, P., Arnberger, A., Allex, B., Wiesbock, L., Wanka, A Kolland, F., Eder, R., Hutter, H.P., Kutalek, R. Vulnerability to heatwaves and implications for public health interventions - A scoping review. Environmental Research: 2018, 166(10), $42-54$

\begin{tabular}{|c|c|c|c|c|}
\hline \multirow{2}{*}{ Database } & \multicolumn{2}{|l|}{ Query } & \multirow{2}{*}{$\begin{array}{c}\text { Hits (incl. } \\
\text { duplicate } \\
\text { s) }\end{array}$} & \multirow{2}{*}{\begin{tabular}{|c|} 
Hits \\
(excl. \\
duplicat \\
es)
\end{tabular}} \\
\hline & $\begin{array}{l}\text { Population*" OR "Disadvantaged" OR "Underserved } \\
\text { Population*" OR "Underserved Patient*") }\end{array}$ & & & \\
\hline SCOPUS & \begin{tabular}{|l} 
( TITLE-ABS ( measure* OR polic* OR intervention* \\
OR plan OR plans OR program* OR response OR \\
evaluat* OR warning* OR alert* OR watch OR "public \\
health response" OR prevention OR preparedness OR \\
strateg* OR "risk management" OR "disaster \\
management" OR "disaster planning" OR "emergency \\
management" OR "relief planning" OR adaptation OR \\
adaption OR approach*) OR KEY ( "Disaster \\
Planning")) AND ( TITLE-ABS ( health OR "heat \\
related illness*" OR "Heat Stress Disorder*" OR "Heat \\
Stress Syndrome*" OR "Heat Cramp*" OR heatstroke* \\
OR "heat strok*" OR sunstroke* OR "Heat \\
Exhaustion" OR "Heat Prostration" OR "Heat \\
Collapse" OR "heat related risk*" OR morbidity OR \\
mortality) OR KEY ( "Heat Stress Disorders")) AND ( \\
TITLE-ABS ( "heat wave*" OR heatwave* OR \\
"extreme heat*" OR "hot temperature*") OR KEY ( \\
"extreme heat" OR "hot temperature") OR ( TITLE- \\
ABS ( hot OR heat) AND KEY ( climate OR heat))) \\
AND ( TITLE-ABS ( vulnerab* OR underserved OR \\
"Sensitive Population*" OR "Disadvantaged" OR \\
"Underserved Population*" OR "Underserved \\
Patient*") OR KEY ( "Vulnerable Populations"))
\end{tabular} & \begin{tabular}{||l} 
AND ( LIMIT- \\
TO ( PUBYEAR, \\
2017) until \\
LIMIT-TO ( \\
PUBYEAR, \\
1995)) AND \\
KEY (animals \\
AND NOT \\
humans)
\end{tabular} & $\mid 545$ & 250 \\
\hline ScienceDirect & \begin{tabular}{|l}
$($ TITLE(measure* OR polic* OR intervention* OR \\
plan OR plans OR program* OR response OR evaluat* \\
OR warning* OR alert* OR watch OR "public health \\
response" OR prevention OR preparedness OR strateg* \\
OR "risk management" OR "disaster management" OR \\
"disaster planning" OR "emergency management" OR \\
"relief planning" OR adaptation OR adaption OR \\
approach*) OR KEY("Disaster Planning")) AND \\
(TITLE(health OR "heat related illness*" OR "Heat \\
Stress Disorder*" OR "Heat Stress Syndrome*" OR \\
"Heat Cramp*" OR heatstroke* OR "heat strok*" OR \\
sunstroke* OR "Heat Exhaustion" OR "Heat \\
Prostration" OR "Heat Collapse" OR "heat related \\
risk*" OR morbidity OR mortality) OR KEY("Heat \\
Stress Disorders")) AND (TITLE("heat wave*" OR \\
heatwave* OR "extreme heat*" OR "hot \\
temperature*") OR KEY("extreme heat" OR "hot \\
temperature") OR (TITLE(hot OR heat) AND \\
KEY(climate OR Heat))) AND (TITLE(vulnerab* OR \\
underserved OR "Sensitive Population*" OR \\
"Disadvantaged" OR "Underserved Population*" OR \\
"Underserved Patient*") OR KEY("Vulnerable
\end{tabular} & pub-date $>1994$ & 126 & 32 \\
\hline
\end{tabular}


Mayrhuber, E.S., Dückers, M.L.A., Wallner, P., Arnberger, A., Allex, B., Wiesbock, L., Wanka, A Kolland, F., Eder, R., Hutter, H.P., Kutalek, R. Vulnerability to heatwaves and implications for public health interventions - A scoping review. Environmental Research: 2018, 166(10), $42-54$

\begin{tabular}{|c|c|c|c|c|}
\hline \multirow{2}{*}{ Database } & \multicolumn{2}{|l|}{ Query } & $\begin{array}{l}\text { Hits (incl. } \\
\text { duplicate } \\
\text { s) }\end{array}$ & \begin{tabular}{|c|} 
Hits \\
(excl. \\
duplicat \\
es)
\end{tabular} \\
\hline & \begin{tabular}{|l|} 
Populations"))) \\
((ABS(measure* OR polic* OR intervention* OR plan \\
OR plans OR program* OR response OR evaluat* OR \\
warning* OR alert* OR watch OR "public health \\
response" OR prevention OR preparedness OR strateg* \\
OR "risk management" OR "disaster management" OR \\
"disaster planning" OR "emergency management" OR \\
"relief planning" OR adaptation OR adaption OR \\
approach*) OR KEY("Disaster Planning")) AND \\
(ABS(health OR "heat related illness*" OR "Heat \\
Stress Disorde**" OR "Heat Stress Syndrome*" OR \\
"Heat Cramp*" OR heatstroke* OR "heat strok*" OR \\
sunstroke* OR "Heat Exhaustion" OR "Heat \\
Prostration" OR "Heat Collapse" OR "heat related \\
risk*" OR morbidity OR mortality) OR KEY("Heat \\
Stress Disorders")) AND (ABS("heat wave*" OR \\
heatwave* OR "extreme heat*" OR "hot \\
temperature*") OR KEY("extreme heat" OR "hot \\
temperature") OR (ABS(hot OR heat) AND \\
KEY(climate OR Heat))) AND (ABS(vulnerab* OR \\
underserved OR "Sensitive Population*" OR \\
"Disadvantaged" OR "Underserved Population*" OR \\
"Underserved Patient*") OR KEY("Vulnerable \\
Populations"))) \\
\end{tabular} & \begin{tabular}{||l||l} 
\\
\\
pub- \\
date $>1994$ AND \\
NOT \\
KEY(animals \\
AND NOT \\
humans) \\
\\
\end{tabular} & & \\
\hline $\begin{array}{l}\text { Psychinfo } \\
\text { (Ovid) }\end{array}$ & \begin{tabular}{|l|} 
measure* or polic* or intervention* or plan or plans or \\
program* or response or evaluat* or warning* or alert* \\
or watch or "public health response" or prevention or \\
preparedness or strateg* or "risk management" or \\
"disaster management" or "disaster planning" or \\
"emergency management" or "relief planning" or \\
adaptation or adaption or approach*).ti,ab. or \\
Emergency Preparedness/ AND (health or "heat related \\
illnes*" or "Heat Stress Disorder*" or "Heat Stress \\
Syndrome*" or "Heat Cramp*" or heatstroke* or "heat \\
strok*" or sunstroke* or "Heat Exhaustion" or "Heat \\
Prostration" or "Heat Collapse" or "heat related risk*" \\
or morbidity or mortality).ti,ab. or "Heat Effects"/ \\
AND ("heat wave*" or heatwave* or "extreme heat*" \\
or "hot temperature*").ti,ab. or ((hot or heat).ti,ab. and \\
(exp "Climate Change"/ or "Heat Effects")) AND \\
(vulnerab* or underserved or "Sensitive Population*" \\
or "Disadvantaged" or "Underserved Population*" or \\
"Underserved Patient*").ti,ab. or "At Risk \\
Populations"/
\end{tabular} & \begin{tabular}{||l} 
\\
\\
limit to \\
yr="1995- \\
Current" AND \\
not (Animal not \\
Human).po. \\
\\
\\
\end{tabular} & 22 & 13 \\
\hline Embase (Ovid) & $\begin{array}{l}\text { (measure* or polic* or intervention* or plan or plans or } \\
\text { program* or response or evaluat* or warning* or alert* } \\
\text { or watch or "public health response" or prevention or }\end{array}$ & $\begin{array}{l}\text { limit to yr/"1995 - } \\
\text { Current" AND } \\
\operatorname{not}((\exp \end{array}$ & 365 & 99 \\
\hline
\end{tabular}


Mayrhuber, E.S., Dückers, M.L.A., Wallner, P., Arnberger, A., Allex, B., Wiesbock, L., Wanka, A/ग Kolland, F., Eder, R., Hutter, H.P., Kutalek, R. Vulnerability to heatwaves and implications for public health interventions - A scoping review. Environmental Research: 2018, 166(10), $42-54$

\begin{tabular}{|c|c|c|c|c|}
\hline \multirow{2}{*}{ Database } & \multicolumn{2}{|l|}{ Query } & \begin{tabular}{|} 
Hits (incl. \\
duplicate \\
s)
\end{tabular} & \begin{tabular}{|c} 
Hits \\
(excl. \\
duplicat \\
es)
\end{tabular} \\
\hline & $\begin{array}{l}\text { preparedness or strateg* or "risk management" or } \\
\text { "disaster management" or "disaster planning" or } \\
\text { "emergency management" or "relief planning" or } \\
\text { adaptation or adaption or approach*).ti,ab. or disaster } \\
\text { planning/ AND (health or "heat related illness*" or } \\
\text { "Heat Stress Disorder*" or "Heat Stress Syndrome*" or } \\
\text { "Heat Cramp*" or heatstroke* or "heat strok*" or } \\
\text { sunstroke* or "Heat Exhaustion" or "Heat Prostration" } \\
\text { or "Heat Collapse" or "heat related risk*" or morbidity } \\
\text { or mortality).ti,ab. or exp heat injury/ AND ("heat } \\
\text { wave*" or heatwave* or "extreme heat*" or "hot } \\
\text { temperature*").ti,ab. or ((hot or heat).ti,ab. and (heat/ } \\
\text { or "Climate Change"/)) AND (vulnerab* or } \\
\text { underserved or "Sensitive Population*" or } \\
\text { "Disadvantaged" or "Underserved Population*" or } \\
\text { "Underserved Patient*").ti,ab. or "high risk } \\
\text { population"/ or vulnerable population/ }\end{array}$ & $\begin{array}{l}\text { animal/or } \\
\text { nonhuman/) not } \\
\text { exp human/) }\end{array}$ & & \\
\hline & & & 1598 & 784 \\
\hline
\end{tabular}


Mayrhuber, E.S., Dückers, M.L.A., Wallner, P., Arnberger, A., Allex, B., Wiesbock, L., Wanka, A Kolland, F., Eder, R., Hutter, H.P., Kutalek, R. Vulnerability to heatwaves and implications for public health interventions - A scoping review. Environmental Research: 2018, 166(10), $42-54$

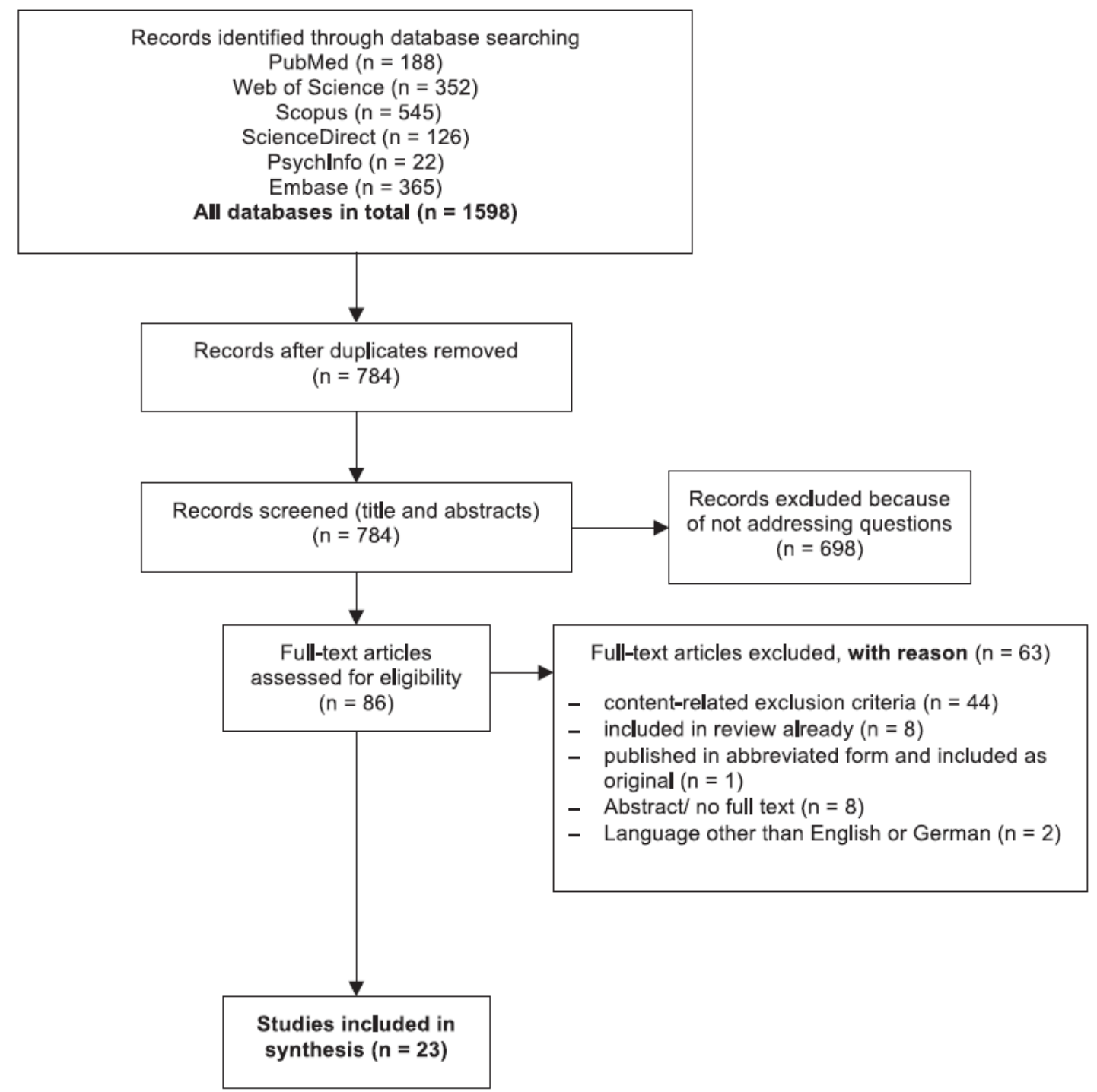

Fig. 1. Flow diagram of study selection process.

Table 2. Profile of studies.

\begin{tabular}{|c|c|c|c|c|}
\hline Author & Year & Country & No & Study design \\
\hline $\begin{array}{c}\text { Lowe, D., K.L. Ebi and B. } \\
\text { Forsberg }\end{array}$ & 2011 & $\begin{array}{l}\text { Belgium, France, Germany, } \\
\text { Hungary, Italy, Macedonia, } \\
\text { Netherlands, Portugal, } \\
\text { Romania, Spain, UK, } \\
\text { Switzerland }\end{array}$ & 12 & $\begin{array}{l}\text { Scoping review to identify and } \\
\text { characterize heatwave early warning } \\
\text { systems in European countries }\end{array}$ \\
\hline Grewe, H.A. and B. Blättner & 2011 & $\begin{array}{l}\text { Belgium, Denmark, England, } \\
\text { France, Italy, Luxembourg, } \\
\text { Netherlands, Portugal, Spain } \\
\end{array}$ & 9 & $\begin{array}{l}\text { Overview, description of heat health } \\
\text { action plans }\end{array}$ \\
\hline $\begin{array}{l}\text { Mees, H.L.P., P.P.J. Driessen } \\
\text { and H. A.C. Runhaar }\end{array}$ & 2015 & $\begin{array}{l}\text { The Netherlands and ten } \\
\text { cities: Chicago, Kassel, } \\
\text { London, New York, Paris, } \\
\text { Philadelphia, Rome, Stuttgart, } \\
\text { Tatabanya, Toronto }\end{array}$ & 8 & $\begin{array}{l}\text { Two interactive multi-stakeholder } \\
\text { workshops in Arnhem \& Rotterdam } \\
\text { (63 participants), one focus group of } \\
\text { elderly people in Rotterdam (14 } \\
\text { participants), and a content analysis } \\
\text { of relevant literature, reports, local }\end{array}$ \\
\hline
\end{tabular}


Mayrhuber, E.S., Dückers, M.L.A., Wallner, P., Arnberger, A., Allex, B., Wiesbock, L., Wanka, A Kolland, F., Eder, R., Hutter, H.P., Kutalek, R. Vulnerability to heatwaves and implications for

\begin{tabular}{|c|c|c|c|c|}
\hline Author & Year & Country & No & Study design \\
\hline & & & & policy documents \& internet sites; \\
\hline Kovats, R.S. and K.L. Ebi & 2006 & $\begin{array}{l}\text { Italy (city-level } \\
\text { implementation), France (all } \\
14 \text { main cities), Spain, UK } \\
\text { (UK Heatwave Plan for } \\
\text { England and Wales), Portugal } \\
\text { (country-wide), Germany } \\
\text { (country-wide) }\end{array}$ & 6 & $\begin{array}{l}\text { Report on heatwaves and public } \\
\text { health in Europe }\end{array}$ \\
\hline $\begin{array}{l}\text { Paz, S., M. Negev, A. Clermont } \\
\text { and M.S. Green }\end{array}$ & 2016 & $\begin{array}{l}5 \text { Med-cities: Adelaide, } \\
\text { Barcelona, Cape Town, Los } \\
\text { Angeles, Santiago }\end{array}$ & 5 & $\begin{array}{l}\text { Literature review and analysis, } \\
\text { descriptive results }\end{array}$ \\
\hline $\begin{array}{c}\text { Van Loenhout, J.A. F., J.M. } \\
\text { Rodriguez-Llanes and D. Guha- } \\
\text { Sapir }\end{array}$ & 2016 & Belgium, The Netherlands & 2 & $\begin{array}{l}\text { Desk evaluation of National } \\
\text { Heatwave Plans and key informant } \\
\text { interviews }\end{array}$ \\
\hline $\begin{array}{l}\text { Paterson, J.A., J.D. Ford, L.B. } \\
\text { Ford, A. Lesnikowski, P. Berry, } \\
\text { J. Henderson and J. Heymann }\end{array}$ & 2012 & Ontario, Canada & 1 & $\begin{array}{l}\text { Qualitative interview study: } 53 \\
\text { semi-structured interviews were } \\
\text { conducted to identify adaptation } \\
\text { efforts, barriers and opportunities for } \\
\text { current and future interventions } \\
\end{array}$ \\
\hline Boeckmann, $\mathrm{M}$. & 2016 & Japan & 1 & $\begin{array}{l}\text { Qualitative study of local heat and } \\
\text { climate change adaptation, } \\
\text { explorative approach }\end{array}$ \\
\hline $\begin{array}{c}\text { Martinez, G.S., C. Imai and K. } \\
\text { Masumo }\end{array}$ & 2011 & $\begin{array}{l}\text { Municipalities: Kusatsu } \\
\text { (Shiga), Kumagaya (Saitama), } \\
\text { Tajimi (Gifu), Obu (Aichi), } \\
\text { Machida (Tokyo) in Japan } \\
\end{array}$ & $\| 1$ & $\begin{array}{l}\text { Review, internet search and } \\
\text { interviews }\end{array}$ \\
\hline Kunst, A.E. and R. Britstra & 2013 & The Netherlands & 1 & $\begin{array}{l}\text { Implementation evaluation, } 27 \\
\text { questionnaires obtained from care } \\
\text { managers of long-term care } \\
\text { institutions in Amsterdam } \\
\end{array}$ \\
\hline Martin, J.L. & 2016 & Baltimore City, US & 1 & $\begin{array}{l}\text { Description of Baltimore City Code } \\
\text { Red Program }\end{array}$ \\
\hline $\begin{array}{c}\text { O'Neill, M.S., D.K. Jackman, M. } \\
\text { Wyman, X. Manarolla, C.J. } \\
\text { Gronlund, D.G. Brown, S.J. } \\
\text { Brines, J. Schwartz and A.V. } \\
\text { Diez-Roux } \\
\end{array}$ & 2010 & 285 US communities & 1 & $\begin{array}{l}\text { Survey of } 285 \text { communities on local } \\
\text { government programs to prevent } \\
\text { health problems and reduce heat } \\
\text { exposure }\end{array}$ \\
\hline $\begin{array}{c}\text { White-Newsome, J.L., S. } \\
\text { McCormick, N. Sampson, M.A. } \\
\text { Buxton, M.S. O'Neill, C.J. } \\
\text { Gronlund, L. Catalano, K.C. } \\
\text { Conlon and E.A. Parker }\end{array}$ & 2014 & $\begin{array}{l}\text { Cities: Detroit, New York } \\
\text { City, Philadelphia, Phoenix in } \\
\text { the US }\end{array}$ & 1 & $\begin{array}{l}\text { Qualitative interview study (73 } \\
\text { semi-structured interviews with gov. } \\
\& \text { non-gov organization leaders rep. } \\
\text { public health, general social } \\
\text { services, emergency management, } \\
\text { meteorology, and the environmental } \\
\text { planning sectors) }\end{array}$ \\
\hline $\begin{array}{c}\text { Kosatsky, T., N. King and B. } \\
\text { Henry }\end{array}$ & 2005 & $\begin{array}{l}\text { Cities Toronto and Montreal } \\
\text { in Canada }\end{array}$ & 1 & $\begin{array}{l}\text { Description of predictive heat/health } \\
\text { warning (alert) system and Hot } \\
\text { Weather Response Plan }\end{array}$ \\
\hline
\end{tabular}




\begin{tabular}{|c|c|c|c|c|}
\hline Author & Year & Country & No & Study design \\
\hline Price, K., S. Perron and N. King & 2013 & Montreal in Canada & 1 & Implementation description \\
\hline \begin{tabular}{|c|} 
Knowlton, K., S.P. Kulkarni, G. \\
S. Azhar, D. Mavalankar, A. \\
Jaiswal, M. Connolly, A. Nori- \\
Sarma, A. Rajiva, P. Dutta, B. \\
Deol, L. Sanchez, R. Khosla, P.J. \\
Webster, V.E. Toma, P. \\
Sheffield and J. J. Hess \\
\end{tabular} & 2014 & Ahmedabad, Gujarat, India & 1 & $\begin{array}{l}\text { Description of development and } \\
\text { implementation of the heat-health } \\
\text { action plan and the heat early } \\
\text { warning system in Ahmedabad }\end{array}$ \\
\hline \begin{tabular}{|c|} 
Michelozzi, P., F.K. de' Donato, \\
A.M. Bargagli, D. D'Ippoliti, M. \\
de Sario, C. Marino, P. Schifano, \\
G. Cappai, M. Leone, U. \\
Kirchmayer, M. Ventura, M. di \\
Gennaro, M. Leonardi, F. \\
Oleari, A. de Martino and C.A. \\
Perucci \\
\end{tabular} & 2010 & 34 major cities in Italy & 1 & $\begin{array}{l}\text { Description of the Italian National } \\
\text { Program for the prevention of heat- } \\
\text { health effects }\end{array}$ \\
\hline $\begin{array}{c}\text { Grewe, H.A. and D. } \\
\text { Pfaffenberger }\end{array}$ & 2011 & Germany & 1 & Review (not specified) \\
\hline Bolitho, A. and F. Miller & 2016 & Australia & 1 & $\begin{array}{l}\text { Qualitative study: literature and } \\
\text { policy review; analysis of available } \\
\text { secondary data on extreme heat } \\
\text { events and impacts and structured, } \\
\text { key informant interviews with } \\
\text { stakeholders }\end{array}$ \\
\hline $\begin{array}{c}\text { Berisha, V., D. Hondula, M. } \\
\text { Roach, J.R. White, B. } \\
\text { McKinney, D. Bentz, A. } \\
\text { Mohamed, J. Uebelherr and K. } \\
\text { Goodin }\end{array}$ & 2017 & $\begin{array}{l}\text { Maricopa County, Arizona, } \\
\text { US }\end{array}$ & 1 & $\begin{array}{l}\text { Evaluation (an observational surveys } \\
\text { at } 63 \text { facilities, a facility } \\
\text { management survey with } 52 \\
\text { managers, a visitor survey } \\
\text { completed by } 658 \text { participants from } \\
22 \text { cooling centers) } \\
\end{array}$ \\
\hline $\begin{array}{c}\text { Riley, K., L. Delp, D. Cornelio } \\
\text { and S. Jacobs }\end{array}$ & 2012 & California, US & 1 & $\begin{array}{l}\text { Description of an outreach and } \\
\text { education approach, feedback from } \\
\text { participants }\end{array}$ \\
\hline Bassil, K.L. and D. C. Cole & 2010 & 14 studies reviewed & 15 & Structured review \\
\hline $\begin{array}{l}\text { Toloo, G., G. FitzGerald, P. } \\
\text { Aitken, K. Verrall and S. Tong }\end{array}$ & 2013 & 15 studies reviewed & 16 & Systematic literature search \\
\hline
\end{tabular}


Mayrhuber, E.S., Dückers, M.L.A., Wallner, P., Arnberger, A., Allex, B., Wiesbock, L., Wanka, A円 Kolland, F., Eder, R., Hutter, H.P., Kutalek, R. Vulnerability to heatwaves and implications for public health interventions - A scoping review. Environmental Research: 2018, 166(10), 4254

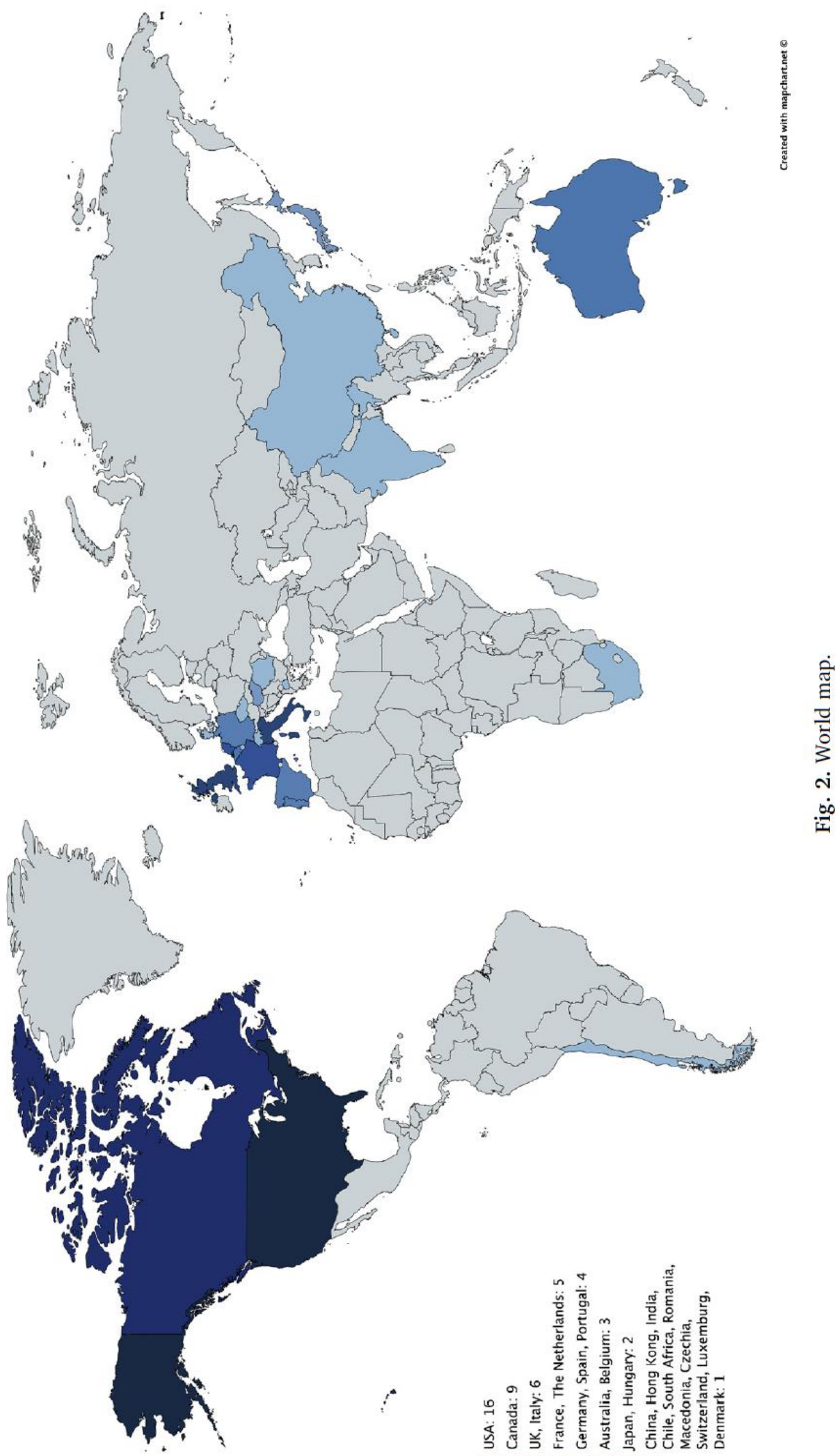




\section{Table 6: Reviews on effectiveness}

Author, year Studies included with countries

Bassil, K. L. $\quad$ Abrahamson 2008: UK1;

and D. C. Angus 2006: Canada;

Cole Ebi et al. 2004 US:

Fouillet et al. 2008: France1;

INPES 2006: US;

Kalkstein et al. 2007: US;

Kosatsky et al. 2009: Canada1;

Kysely \& Kriz 2008: Czech

Republic;

Nogueria et al. 2005: Portugal;

Palecki et al 2001: US;

Sheridan 2007: US \& Canada1;

Smoyer 1997: US;

Smoyer 1998: US1;

Weisskopf et al. 2002: US

Effectiveness of public health

interventions in:

- public awareness and individual

change in practice

- change in health outcomes

(morbidity and mortality)

(14 studies)

Italy;

Palecki et al. 2001: Midwest USA2; Tan et al. 2007: Shanghai, China;

Weisskopf et al. 2002: Milwaukee, USA2

Effectiveness heat warning in reducing health impacts

\section{(7 studies)}

Abrahamson et al. 2008: London

and Norwich, UK1, 2

Alberini et al. 2011: 5 cities

Canada1;

Ibrahim et al. 2012 Victoria,

Australia;

Kalkstein and Sheridan 2007:

Phoenix, USA2;

Richard et al. 2011: Montreal

Canada1;

Semenza et al. 2008b Houston and

Portland, USA:

Sheridan 2007: 4 cities in North

America1, 2;

Wolf et al. 2010: Norwich UK1

Effectiveness heat warning in

alerting human response

(8 studies) se staff, general

public,

cardiac/pulmonary

patients,

elderly/health care

providers and

mortality/morbidity

assessed in

different defined

groups

For reducing health

impacts look at

excess mortality for

$>65$ age group,

odds of increasing

mortality among

age groups $65-74$

and $>75$

\section{For alerting human} response: elderly 72-94, communitybased health

profession and care providers to people aged $>65$, middle aged and older with heart problems,
Indicators of awareness and practice are difficult to measure e.g. received heat-line calls decreased with summer progression likely due to less media attention, less advertising and reduced need given acclimatization

- vulnerable, elderly and socially isolated may be less aware than general public

- public surveys: knowledge of heat warning is often universal, but e.g. elderly and less-educated were less likely to heed advice

- recall of heat alerts from radio and television broadcasts may be high and associated with increasing level of change in practice, as well as increased efforts to support vulnerable friends and family (73\%) (although fewer elderly reported having been helped (63\%) and only $14 \%$ reported asking for help) (INPES 2006)

- variation in awareness across different demographic categories, and despite nearly universal awareness of heat advisory it did not necessarily translate into action (only $50 \%$ Kalkstein et al. 2007)

- perception studies may not capture important vulnerable groups like socially isolated or homeless

- in over 65 year olds knowledge of details of message of mitigation plans were less well understood, few changed

practice because did not believe they were vulnerable or messages applied to them, also confusion with ozone

precautions

- self-perception and challenge in delivering targeted strategies e.g. people with chronic cardiac and pulmonary disease did consider themselves at-risk

- elderly not concerned about heat or not taking advantages of resources

- concern over whether information was reaching vulnerable populations, recommendation to focus more (i.e. women over 85 years living alone)

Change in health outcome: number of lives saved and economic benefit of warnings assessed in Philadelphia where warning lowered mortality by 2.6 lives with operational costs at noise level, but it remains challenging to assign such tangible values.

- commonly comparison between different heat wave periods, challenge greater public awareness of heat-warnings - heat-related mortality rates and ambulance services, challenge may be attributable to improvements in response - heat wave may be more severe and longer, increase in AC availability and improved response, increase in "frail elderly" population, rising poverty rates, etc.

Effectiveness in reducing heat-related mortality: six studies asserted that substantially fewer people died of excessive heat after implementation of heat warning systems, comparing hot period without system in place with similarly hot period with a system implemented, to be considered to have an effect: other factors such as overall improvements in health care, better living conditions incl. use of $\mathrm{AC}$, heightened heat awareness, use of heat insulating building materials.

Effectiveness in reducing heat-related morbidity: no studies measured the potential impacts of system to reduce morbidity.

- studies measured emergency medical service, emergency hospital admission, calls to ambulance during heat waves; overall contrasting patterns between hospital admission and mortalities during heatwaves.

Cost-effectiveness (Ebi et al. 2004)

Human response and effectiveness: warnings intended to increase awareness of risk associated with heat and provide temporary measures to safeguard the population's health, measures include opening of cooling shelters, use of "buddy" systems, distribution of hydration packs; coupled with mass media messages to warn the public, ways to protect themselves and others, and availability of facilities - very few papers addressed whether programs reach and are heeded by the target audience;

Awareness, perception and action: does awareness lead to taking protective actions? Those who saw themselves vulnerable were more likely to take actions, those who did not consider themselves susceptible were less likely to act to protect themselves, e.g. some elderly did not consider themselves vulnerable but others of the same age group; - few people have knowledge on thermoregulation, hot temperature threshold, sweating and use of fans

Summer preparedness: unchanged behavior is explained by the fact that many people naturally change their behavior in the summer - it could be people's "common sense" to protect themselves, but important to notice that this may have detrimental effects on vulnerable and isolated people whose conditions may deteriorate rapidly.

Cost and barriers: especially cost of running an AC (Sheridan, 2007). 
Recommendation for criteria for evaluation: A process evaluation of the system is recommended describe the components and operation of the system; describe the resources used to operate the system, evaluate the system for simplicity, acceptability, sensitivity, timeliness, effectiveness of individual response measures, specificity.

Grewe, H. A. and B. Blättner

The joint progr

\section{The study was not designed to assess whether the heat plan, as applied in 2010, was effective in reducing mortality.}

Continuous quality improvement efforts were applied and several issues have been identified and address, linked to what the study group consider effective elements of the project: recognition of heat as a disaster and growing health threat; interagency communication and
coordination; international team coordination; data collection; budgetary concerns and political will. A program evaluation is intended and includes coordination; international team coordination; data collection; budgetary concerns and political will. A program evaluation is intended and include
assessment of its effect on two main target populations: organizations involved in the public health response to extreme heat, and the general assessment of its effect on two main target populations: organizations involved in the public health respons
population, particularly people most vulnerable to extreme heat (ongoing when the study was published).

population, particularly people most vulnerable to extreme heat (ongoing when the study was published).
Other evaluation activities are being planned, especially impact assessment and efficiency characterization. Impacts assessment in the general Other evaluation activities are being planned, especially impact assessment and efficiency characterization. Impacts assessment in the general
population will include: post-intervention surveys of vulnerable populations (e.g. slum households); review of emergency medical service, hospital, population will include: post-intervention surveys of vulnerable populations (e.g. slum households); review of emergency medical service, hospital,
clinic records, and evaluation of post-intervention all-cause mortality records for the city. Self-reported rates of heat illness and prevalence of hot weather coping behaviors in slum dwellers will be compared to baseline rates collected prior to the interventions, from emergency medical service calls, visits to clinics, and hospital admissions for all-causes and heat-specific causes.

Once impact evaluations have been done, efficiency and cost-effectiveness of the intervention can be evaluated.

Michelozzi, P., et al. 2010 The mortality surveillance system enables the evaluation of warning systems and prevention programs, but the critical point is that the potential effectiveness of interventions, included in the heat prevention plans, still need to be formally evaluated.

Evaluation of heat prevention plans as a whole is another critical issue and despite difficulties, process and outcome assessments should be undertaken. A preliminary evaluation carried out in Italy suggests that a reduction in the impact of heat on mortality has occurred since the introduction of HHWWS and prevention programs, but alternative explanations cannot be disregarded. With reference to other literature the introduction of
authors emphasize that there is a general consensus that more has to be done in terms of evaluation of heat health watch warning systems and prevention measures.

Grewe, H. A. et al. 2011 Effectiveness of most individual measures is not tested, however, measures to optimize liquid and electrolyte balance, cardio-vascular function as well as bodily heat release and heat production are linked to evidence on susceptibility and its reduction. 
